\title{
ON ACCURATE ESTIMATION OF TRANSVERSE STRESSES IN MULTILAYER LAMINATES
}

\author{
T. Kant† and B. S. Manjunatha \\ Department of Civil Engineering, Indian Institute of Technology, Powai, Bombay-400 076, India
}

(Received 30 July 1992)

\begin{abstract}
New numerical algorithms are proposed for the accurate evaluation of transverse stresses in general composite and sandwich laminates. A set of higher-order theories with $C^{0}$ isoparameteric finite elements and exact three-dimensional equilibrium equations are used. The integration of the equilibrium equations is carried out through exact surface fitting method, direct integration method and forward and central direct finite difference methods. Sixteen- and nine-noded quadrilateral Lagrangian elements with selective numerical integration techniques based on Gauss-Legendre product rules are used in the analysis. Validity of the present numerical techniques and the higher-order theories are demonstrated by comparing the present results with the available elasticity and other closed-form solutions for cross-ply, angle-ply and sandwich laminates. The exact surface fitting method is seen to give accurate estimate of the transverse stresses compared to other methods.
\end{abstract}

\section{INTRODUCTION}

Composite materials are currently enjoying a variety of engineering applications and their strength and weaknesses are beginning to be properly appreciated by designers, and they are being employed in a more rational manner [1]. One form of these materials, being used in current design studies for aircraft, is the unidirectional fibre reinforced plastic lamina. Consequently, these design studies incorporate structural elements such as plates and shells which are fabricated from a number of unidirectional laminae and the desired strength/stiffness properties of these elements are achieved by suitably orienting the laminae relative to the plate or shell principal axes.

In many instances these laminate structural elements will be moderately thick in relation to their span dimensions and in consequence of this a more refined analysis, one that takes into account transverse shear deformation, is required if the flexure response is to be adequately predicted. The classical lamination theory based on the Kirchhoff hypothesis [1] and the first-order shear deformation theories based on Reissner [2] and Mindlin [3] cannot be employed for this analysis. This is because the classical lamination theory ignores the effect of transverse shear deformation, normal stress/strain and nonlinear in-plane normal strain distribution through the laminate thickness [1] and the first-order shear deformation theory even though it considers the effect of transverse shear deformation, but assumes it as constant, thus a fictitious shear correction coefficient is used to correct the strain energy of deformation. To overcome all these discrepancies, Reissner [4],

† To whom all correspondence should be addressed.
Lo et al. [5, 6] and Kant [7] presented higher-order theories which take care of the shear deformation, transverse normal stress/strain effects. Kant et al. [8] were the first to present a $C^{0}$ finite element formulation of a higher-order theory.

Pandya and Kant [9-11] and Kant and Manjunatha $[12,13]$ have extended this theory for general composite and sandwich laminates. Reddy [14], Phan and Reddy [15] and Pucha and Reddy [16] have presented a closed-form, $C^{1}$ displacement finite element and $C^{0}$ mixed finite element formulations, respectively, of a theory based on a displacement model given by Murthy [17] and Levinson [18]. But these neglect the effects of transverse normal stress/strain. Pandya and Kant [11] have also given a novel approach of imposing the zero transverse shear stress conditions on top and bottom bounding planes of the laminates by modifying the shear rigidity matrix instead of the displacement model $[14,17,19]$.

Further, in the evaluation of in-plane and transverse stresses, the constitutive relation can be used to accurately evaluate the in-plane stresses, but the same cannot be used for the evaluation of transverse stresses as it violates the continuity of these stresses at the interfaces. Thus, transverse stresses are generally evaluated by using the three-dimensional equilibrium equations. Engblom and Ochoa $[20,21]$ have modified the displacement field to specify element behaviour and to get a good estimate of in-plane and transverse stresses by using higher-order theories. But, in estimation of these stresses, the formulation obtains $n$ equations in $n-1$ unknowns, thus the equations set becomes overdetermined. These equations are solved by utilizing a least square orthonormalization procedure. 
The main aim of the present work is to accurately evaluate the transverse shear and normal stresses by using three-dimensional equilibrium equations. The integration of the equilibrium equations is attempted through direct integration method, forward and central direct finite difference methods and a new approach called exact surface fitting method. The numerical results obtained by these methods for different models are compared with the available two-dimensional finite element [14-21], elasticity $[22,23]$ and two-dimensional closedform [24-27] solutions.

\section{THEORY AND FORMULATIONS}

The formulations are developed with the assumption of displacement (Fig. 1) models for an anisotropic laminate in the following form

\section{HOST7}

$$
\begin{aligned}
& u(x, y, z)=u_{0}(x, y)+z \theta_{x}(x, y)+z^{3} \theta_{x}^{*}(x, y) \\
& v(x, y, z)=v_{0}(x, y)+z \theta_{y}(x, y)+z^{3} \theta_{y}^{*}(x, y) \\
& w(x, y, z)=w_{0}(x, y)
\end{aligned}
$$

\section{HOST9}

$$
\begin{aligned}
u(x, y, z)= & u_{0}(x, y)+z \theta_{x}(x, y) \\
& +z^{2} u_{0}^{*}(x, y)+z^{3} \theta_{x}^{*}(x, y) \\
v(x, y, z)= & v_{0}(x, y)+z \theta_{v}(x, y) \\
& +z^{2} v_{0}^{*}(x, y)+z^{3} \theta_{\xi}^{*}(x, y) \\
w(x, y, z)= & w_{0}(x, y)
\end{aligned}
$$

\section{HOST11}

$$
\begin{aligned}
u(x, y, z)= & u_{0}(x, y)+z \theta_{x}(x, y) \\
& +z^{2} u_{0}^{*}(x, y)+z^{3} \theta_{x}^{*}(x, y) \\
v(x, y, z)= & v_{0}(x, y)+z \theta_{y}(x, y) \\
& +z^{2} v_{0}^{*}(x, y)+z^{3} \theta_{y}^{*}(x, y) \\
w(x, y, z)= & w_{0}(x, y)+z \theta_{z}(x, y)+z^{2} w_{0}^{*}(x, y)
\end{aligned}
$$

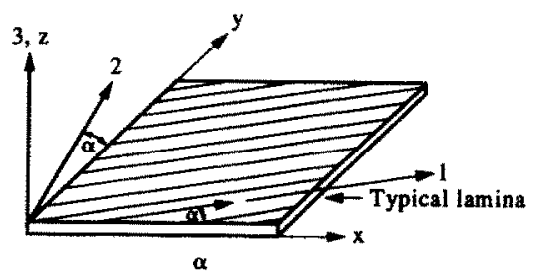

$(1,2,3)$ - Lamina reference axes

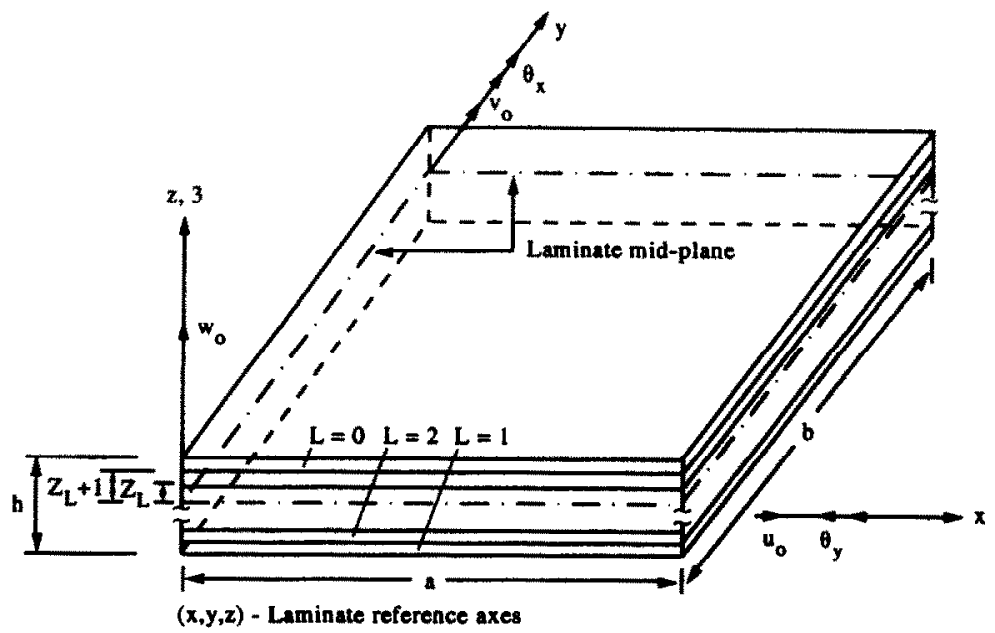

Fig. 1. Laminate geometry with positive set of lamina/laminate reference axes, displacement components and fibre orientation. 
HOST12

$$
\begin{aligned}
u(x, y, z)= & u_{0}(x, y)+z \theta_{x}(x, y)+z^{2} u_{0}^{*}(x, y) \\
& +z^{3} \theta_{x}^{*}(x, y) \\
v(x, y, z)= & v_{0}(x, y)+z \theta_{y}(x, y)+z^{2} v_{0}^{*}(x, y) \\
& +z^{3} \theta_{y}^{*}(x, y) \\
w(x, y, z)= & w_{0}(x, y)+z \theta_{z}(x, y)+z^{2} w_{0}^{*}(x, y) \\
& +z^{3} \theta_{z}^{*}(x, y) .
\end{aligned}
$$

In the above relations, the terms $u, v$ and $w$ are the displacements of a general point $(x, y, z)$ in the laminate domain in the $x, y$ and $z$ directions respectively. The parameters $u_{0}, v_{0}$ are the in-plane displacements and $w_{0}$ is the transverse displacement of a point $(x, y)$ on the middle plane. The functions $\theta_{x}, \theta_{y}$ are rotations of the normal to the middle plane about $y$ and $x$ axes, respectively. The parameters $u_{0}^{*}$, $v_{0}^{*}, w_{0}^{*}, \theta_{x}^{*}, \theta_{y}^{*}, \theta_{z}^{*}$ and $\theta_{z}$ are the higher-order terms in the Taylor's series expansion and they represent higher-order transverse cross sectional deformation modes.

The full three-dimensional and its reduced forms of strain displacement and constitutive relations appropriate to the chosen displacement models are used in this formulation [9-13,31]. The theories based on the above higher-order displacement models lead to non-vanishing transverse shear and normal stresses on the top and bottom bounding planes of the laminate. Pandya and Kant [11] have modified the shear rigidity matrix as against the displacement model $[14,17,19]$ to incorporate the zero shear conditions. Their technique retains the $C^{0}$ continuity of displacements including the higher-order ones. This procedure is used for displacement model with seven degrees of freedom (HOST7B). But the results obtained by models which do not satisfy top and bottom zero shear condition are in general better compared to models where this condition is satisfied. This was seen to be more true in the case of thick laminates [11].

The evaluation of transverse stresses $\left(\tau_{x z}, \tau_{y z}, \sigma_{z}\right)$ from the stress-strain constitutive relations leads to discontinuity at the interface of two adjacent layers (laminae) of a laminate and thus violates the equilibrium conditions. The three-dimensional analysis becomes very complex due to the thickness variation of constitutive laws and continuity requirements of transverse stresses and displacements across the interfaces. Thus, elasticity equilibrium equations are used to derive expressions for the transverse stresses in the $L$ th lamina of a multilayered laminate, namely

$$
\begin{aligned}
& \frac{\partial \sigma_{x}}{\partial x}+\frac{\partial \tau_{x y}}{\partial y}+\frac{\partial \tau_{x z}}{\partial z}=0 \\
& \frac{\partial \tau_{x y}}{\partial x}+\frac{\partial \sigma_{y}}{\partial y}+\frac{\partial \tau_{y z}}{\partial z}=0 \\
& \frac{\partial \tau_{x z}}{\partial x}+\frac{\partial \tau_{y z}}{\partial y}+\frac{\partial \sigma_{z}}{\partial z}=0
\end{aligned}
$$

The integration of these equilibrium equations is attempted here through different novel approaches: direct integration method, forward and central direct finite difference methods and a new approach called an exact surface fitting method. These methods are explained below.

\section{(a) Direct integration method}

The three differential equations of equilibrium given by eqns $(5)-(7)$ give three relations, namely,

$$
\begin{aligned}
& \frac{\partial \tau_{x z}}{\partial z}=-\left(\frac{\partial \sigma_{x}}{\partial x}+\frac{\partial \tau_{x y}}{\partial y}\right) \\
& \frac{\partial \tau_{y z}}{\partial z}=-\left(\frac{\partial \sigma_{y}}{\partial y}+\frac{\partial \tau_{x y}}{\partial x}\right)
\end{aligned}
$$

and

$$
\frac{\partial^{2} \sigma_{z}}{\partial z^{2}}=\frac{\partial^{2} \sigma_{x}}{\partial x^{2}}+\frac{\partial^{2} \sigma_{y}}{\partial y^{2}}+2 \frac{\partial^{2} \tau_{x y}}{\partial x \partial y}
$$

from which the transverse stresses $\tau_{x z}, \tau_{y z}$ and $\sigma_{z}$ can be evaluated through integration with respect to the laminate thickness $z$. The in-plane stresses $\sigma_{x}$ and $\sigma_{y}$ and the in-plane shear stress $\tau_{x y}$ obtained by constitutive relations are substituted in eqns (8)-(10). It can be seen that eqns (8) and (9) are first-order equations in $\tau_{x z}$ and $\tau_{y z}$. Solving these equations one obtains only one constant of integration, this being an initial value problem. However, this problem is vexing because the value of transverse shear stresses are normally known at both top and bottom boundary surfaces of the laminate. Thus one obtains only a non-unique solution for transverse shear stresses as two prescribed condition for these stresses cannot be simultaneously enforced in the solution. In the case of transverse normal stress [eqn (10)] a second-order equation is obtained. By integrating the second-order differential equation twice, two constants of integration are obtained. These constants of integration can be determined by substituting the two boundary conditions on the top and bottom surfaces of the laminate. 
The final form of the computational algorithms for $\tau_{x z}, \tau_{y z}$ and $\sigma_{z}$ after integration through the laminate thickness can be written as follows:

$$
\begin{aligned}
\left.\tau_{x z}^{L}\right|_{L+1}= & -\sum_{i=1}^{L} \int_{Z_{1}}^{Z_{i+1}}\left(\frac{\partial \sigma_{x}}{\partial x}+\frac{\partial \tau_{x y}}{\partial y}\right) \mathrm{d} z+C_{1} \\
\left.\tau_{y z}^{L}\right|_{L+1}= & -\sum_{i=1}^{L} \int_{Z_{i}}^{Z_{i+1}}\left(\frac{\partial \sigma_{y}}{\partial y}+\frac{\partial \tau_{x y}}{\partial x}\right) \mathrm{d} z+C_{2} \\
\left.\sigma_{z}^{L}\right|_{L+1}= & \sum_{i=1}^{L} \int_{Z_{t}}^{Z_{i+1}}\left(\int _ { Z } \left(\frac{\partial^{2} \sigma_{x}}{\partial x^{2}}+\frac{\partial^{2} \sigma_{y}}{\partial y^{2}}\right.\right. \\
& \left.\left.+2 \frac{\partial^{2} \tau_{x y}}{\partial x \partial y}\right) \mathrm{~d} z\right) \mathrm{d} z+z C_{3}+C_{4} .
\end{aligned}
$$

The constants $C_{1}$ and $C_{2}$ are obtained from the known values of $\tau_{x z}$ and $\tau_{y z}$ at either of the two boundaries at $z= \pm h / 2$ while constants $C_{3}$ and $C_{4}$ are obtained from the known values of $\sigma_{z}$ at $z= \pm h / 2$. However, eqn (13) requires the use of third derivatives of displacements. For this reason cubic sixteen-noded quadrilateral Lagrangian elements in addition to nine-noded elements are used here. The presence of second and third derivatives of displacements in the stress evaluation dictates the use of high degree polynomial elements and further introduction of numerical error in the estimation of transverse shear and normal stresses. Thus, forward and central direct finite difference (FDM) methods and a new approach called exact surface fitting method (ESFM) are proposed to accurately estimate the transverse shear and normal stresses. Here a formulation for sixteen-noded element is presented. The same procedure is also used for nine-noded element.

\section{(b) Finite difference methods}

Here also in-plane stresses are evaluated by using constitutive relations at different Gauss points in an element $(4 \times 4$ sixteen points for sixteen-noded and $3 \times 3$ nine points for nine-noded). After that, the forward difference method (stresses are maximum at the edges of the laminate) is used in the $x-y$ plane to evaluate the derivatives of in-plane stresses at a particular Gauss point inside the element and either a forward difference or a backward difference method is used for the evaluation of the same at the edges of the laminate depending on whether the edge is a positive or negative one. The following equations corresponding to eqns (8) and (9) are obtained

$$
\begin{aligned}
& \frac{\partial \tau_{x z}(G P)}{\partial z}=-A A \\
& \frac{\partial \tau_{y z}(G P)}{\partial z}=-B B
\end{aligned}
$$

$$
\begin{array}{r}
A A=\left[\frac{\sigma_{x}(G P+4)-\sigma_{x}(G P)}{\Delta X}\right] \\
+\left[\frac{\tau_{x y}(G P+1)-\tau_{x y}(G P)}{\Delta Y}\right] \\
B B=\left[\frac{\sigma_{y}(G P+1)-\sigma_{y}(G P)}{\Delta Y}\right] \\
+\left[\frac{\tau_{x y}(G P+4)-\tau_{x y}(G P)}{\Delta X}\right],
\end{array}
$$

where $G P$ is the Gauss point number at which stresses are evaluated and $G P+4$ and $G P+1$ are the next Gauss point numbers in the $x$ and $y$ directions respectively, where the stresses are evaluated.

Forward difference method. The final form of the computational algorithms for $\tau_{r z}$ and $\tau_{y z}$ after using the forward difference operator along the thickness direction in eqns (14) and (15) are written as follows (these are designated as the forward-direct difference method)

$$
\begin{aligned}
& \left.\tau_{x z}^{L}\right|_{z_{L+1}}=\left.\tau_{x z}^{L}\right|_{z_{L}}-[A A]^{L} *\left(z_{L+1}-z_{L}\right) \\
& \left.\tau_{y z}^{L}\right|_{z_{L+1}}=\left.\tau_{y z}^{L}\right|_{z_{L}}-[B B]^{L} *\left(z_{L+1}-z_{L}\right) .
\end{aligned}
$$

Central difference method. The following computational algorithms are obtained for $\tau_{x z}$ and $\tau_{y z}$ after using the central difference operator along the thickness direction in eqns (14) and (15) (these are designated as central-direct difference method) [30]

$$
\begin{aligned}
& {\left[\frac{\tau_{x z\left(z_{L}+1\right.}-\left(1-\alpha^{2}\right) \tau_{x z\left(z_{L}\right)}-\alpha^{2} \tau_{x=\left(z_{L-1}\right)}}{\alpha(\alpha+1)\left(z_{L+1}-z_{L}\right)}\right]=-[A A]} \\
& {\left[\frac{\tau_{y z\left(z_{L}+1\right)}-\left(1-\alpha^{2}\right) \tau_{y z(z L)}-\alpha^{2} \tau_{\left.y z z z_{L-1}\right)}}{\alpha(\alpha+1)\left(z_{L+1}-z_{L}\right)}\right]=-[B B]}
\end{aligned}
$$

in which

$$
\alpha=\frac{\left(z_{L+1}-z_{L}\right)}{\left(z_{L}-z_{L-1}\right)} .
$$

As the central difference method is a two-step non-self-starting method, the forward difference method is used to evaluate the transverse stresses at first step and for subsequent steps central difference method is used. This method can be effectively used for isotopic laminates. For laminates having different isotropic, orthotropic or anisotropic laminae, the in-plane stresses are discontinuous and two values are obtained at an interface of two layers. As the transverse stresses are continuous through the interface of two layers, the derivatives of in-plane stresses must also be continuous through the interface. Thus, an average of the two values at the interface is used in the above techniques. 


\section{(c) Exact surface fitting method}

Here also in-plane stresses are evaluated through constitutive relations at different Gauss points in an element. After obtaining the in-plane stresses acting on lower and upper surfaces of a particular layer, the variation of these stresses over a particular surface of an element can be expressed as a polynomial in laminate axes $(x, y)$ as follows:

$$
\begin{aligned}
\sigma_{x}(z)= & C_{1}^{z}+C_{2}^{z} x+C_{3}^{z} y+C_{4}^{z} x^{2}+C_{5}^{z} x y+C_{6}^{z} y^{2} \\
& +C_{7}^{z} x^{3}+C_{8}^{z} x^{2} y+C_{9}^{z} x y^{2}+C_{10}^{z} y^{3} \\
& +C_{11}^{z} x^{3} y+C_{12}^{z} x^{2} y^{2}+C_{13}^{z} x y^{3}+C_{14}^{z} x^{3} y^{2} \\
& +C_{15}^{z} x^{2} y^{3}+C_{16}^{z} x^{3} y^{3}
\end{aligned}
$$

Similar equations are obtained for $\sigma_{y}$ and $\tau_{x y}$. The parameter in eqn (23), $z$ refers to a particular surface in the laminate at a distance $z$ from the middle plane and this may be the top or bottom surface of a particular lamina or a subset of a particular lamina having same ply orientations. The following equation is obtained by substituting the in-plane stresses at is obtained by subsltituting the in-plane stresses at different Gauss points in an element

$$
\left[\underset{(16 \times 16)}{\mathbf{A}_{i j}}\right]\left[\underset{(16 \times 1)}{\mathbf{C}_{j}^{z}}\right]=\left[\begin{array}{c}
\boldsymbol{\sigma}_{(16 \times 1)}^{z} \\
\mathbf{z} \times 1)
\end{array}\right]
$$

Similar equations are obtained for $\sigma_{y}$ and $\tau_{x y}$. The above equation is solved and the sixteen polynomial constants are obtained. Equation (23) is differentiated with respect to $x$ and $y$ and thus derivatives of in-plane stresses are obtained. These are written as follows:

$$
\frac{\partial \sigma_{x}}{\partial x}=C_{2}^{z}+2 C_{4}^{z} x+C_{5}^{z} y+3 C_{7}^{z} x^{2}+2 C_{8}^{z} x y+C_{9}^{z} y^{2}
$$$$
+3 C_{11}^{2} x^{2} y+2 C_{12}^{z} x y^{2}+C_{13}^{z} y^{3}+3 C_{14}^{z} x^{2} y^{2}
$$$$
+2 C_{15}^{2} x y^{3}+3 C_{16}^{2} x^{2} y^{3}
$$

$$
\frac{\partial^{2} \sigma_{x}}{\partial x^{2}}=2 C_{4}^{z}+6 C_{7}^{z} x+2 C_{8}^{z} y+6 C_{11}^{z} x y+2 C_{12}^{z} y^{2}
$$

$$
+6 C_{14}^{2} x y^{2}+2 C_{15}^{2} y^{3}+6 C_{16}^{z} x y^{3}
$$

Similar equations are obtained for $\sigma_{y}$ and $\tau_{x y}$. These derivatives are then used in eqns ( 8 ) and (9) and the same procedure as used for the direct finite difference method is used following eqns (18)-(22).
The final form of the computational algorithm for $\sigma_{z}$ after using the central difference operator along the thickness direction in eqn (10) is written as follows:

$$
\begin{aligned}
2\left[\frac{\sigma_{z\left(z_{L}+1\right)}-(1+\alpha) \sigma_{z\left(z_{L}\right)}+\alpha \sigma_{z\left(z_{L-1}\right)}}{\alpha(1+\alpha)\left(z_{L+1}-z_{L}\right)^{2}}\right] \\
=\frac{\partial^{2} \sigma_{x}}{\partial x^{2}}+\frac{\partial^{2} \sigma_{y}}{\partial y^{2}}+2 \frac{\partial^{2} \tau_{x y}}{\partial x \partial y} .
\end{aligned}
$$

The double derivatives of in-plane stresses are substituted in eqn (27) and this equation is solved as a boundary value problem by substituting the two boundary conditions for transverse normal stresses at top and bottom surfaces of the laminate.

The displacement models given by eqns (1)-(4) are used in conjunction with $C^{0}$ isoparameteric finite elements in the $x-y$ plane and the same has been explained in detail in [12]. Lagrangian quadrilateral elements with 9 and 16 nodes are used. A selective numerical integration technique based on Gauss-Legendre product rules is used here for the evaluation of the element stiffness properties.

\section{NUMERICAL RESULTS AND DISCUSSION}

To demonstrate the accuracy and efficiency of the present higher-order theories and the new numerical techniques, a set of computer program incorporating the higher-order theories are developed for the elastostatics of general composite and sandwich laminates. All the computations are carried out on a CYBER $180 / 840$ computer in single precision with sixteen significant digits word-length. A computer program based on the Reissner/Mindlin theory has also been developed to support the numerical evaluations of the present formulations. The transverse shear energy terms in the Reissner/Mindlin theory are corrected by using a shear correction coefficient of $5 / 6$ for all the materials used here. Selective numerical integration technique, based on Gauss-Legendre product rules, namely $4 \times 4$ for flexure/membrane and $3 \times 3$ for shear terms has been employed for sixteen-noded elements and $3 \times 3$ for flexure/membrane and $2 \times 2$ for shear terms, has been employed for nine-noded elements in the analysis. Due to biaxial symmetry, only one quadrant of the laminate is considered in the case of crossply laminates and for angle-ply and general sandwich laminates full laminate is considered in the analysis.

The values of in-plane, transverse stresses are evaluated at the Gauss points, whereas the displacements are computed at the nodal points. A $2 \times 2$ mesh (four elements) for cross-ply laminates (quarter laminate) and a $4 \times 4$ mesh (sixteen elements) for angle-ply and general sandwich laminates (full laminate) were seen to give generally converged displacements and stresses for nine-noded elements. Similarly, one element for cross-ply laminates and $2 \times 2$ mesh (four elements) for angle-ply and general 
Table 1. Comparison of maximum transverse displacement and transverse shear stress $\left(\bar{\tau}_{\mathrm{v}}\right)$ for simply supported laminate under sinusoidal loading $(a / h=4)(0 / 90)$

\begin{tabular}{|c|c|c|c|c|c|c|c|}
\hline \multirow[b]{3}{*}{ Source } & \multirow[b]{3}{*}{$\bar{w}_{0}$} & \multicolumn{6}{|c|}{ Transverse shear stress $\bar{\tau}_{\mathrm{rz}}$} \\
\hline & & \multirow[b]{2}{*}{ Constitutive } & \multirow{2}{*}{$\begin{array}{c}\text { Direct } \\
\text { integration }\end{array}$} & \multicolumn{2}{|c|}{ Surface fitting methods } & \multicolumn{2}{|c|}{$\begin{array}{c}\text { Direct } \\
\text { difference methods }\end{array}$} \\
\hline & & & & diff. & diff. & Forward & Central \\
\hline HOST7A $(9 N)$ & 2.032656 & 0.252750 & 0.29600 & 0.301818 & 0.315878 & 0.313515 & 0.299480 \\
\hline HOST7A $(16 N)$ & 2.032188 & 0.275000 & 0.34900 & 0.380743 & 0.363395 & 0.336813 & 0.321558 \\
\hline $\operatorname{HOST7B}(9 \mathrm{~N})$ & 1.956250 & 0.212275 & 0.30050 & 0.319685 & 0.306055 & 0.318048 & 0.304440 \\
\hline $\operatorname{HOST} 7 \mathrm{~B}(16 \mathrm{~N})$ & 1.954688 & 0.211650 & 0.35275 & 0.386018 & 0.369703 & 0.341053 & 0.326630 \\
\hline HOST $9(9 \mathrm{~N})$ & 2.055469 & 0.270000 & 0.29025 & 0.309999 & 0.296528 & 0.307333 & 0.293098 \\
\hline HOST9 $(16 N)$ & 2.055000 & 0.269750 & 0.33775 & 0.371570 & 0.355113 & 0.329003 & 0.314523 \\
\hline HOST11 (9N) & 2.032813 & 0.271500 & 0.28725 & 0.308850 & 0.395635 & 0.306268 & 0.293098 \\
\hline HOST $11(16 N)$ & 2.031250 & 0.271500 & 0.33750 & 0.373483 & 0.356823 & 0.331018 & 0.316575 \\
\hline HOST12 (9N) & 2.032813 & 0.271750 & 0.28775 & 0.309180 & 0.295960 & 0.306523 & 0.293353 \\
\hline HOST12(16N) & 2.031250 & 0.271500 & 0.33700 & 0.372893 & 0.356248 & 0.330755 & 0.316315 \\
\hline FOST $(9 N)$ & 2.149844 & 0.221000 & 0.29825 & 0.315815 & 0.304130 & 0.313343 & 0.301678 \\
\hline $\operatorname{FOST}(16 N)$ & 2.149375 & 0.220850 & 0.34800 & 0.380200 & 0.365805 & 0.336455 & 0.323793 \\
\hline Elasticity [23] & & & 0.31270 & & & & \\
\hline Ren [24] & & & 0.32540 & & & & \\
\hline
\end{tabular}

sandwich laminates were seen to give converged results with sixteen-noded elements. Thus, unless otherwise specified, these discretizations are adopted in this paper.

The displacements, as well as in-plane and transverse stresses are presented here in the non-dimensional form using the following multipliers

$$
\begin{aligned}
\bar{w}_{0} & =\frac{10 E_{2} h^{3} w_{0}(a / 2, b / 2,0)}{q_{0} a^{4}=\frac{\tau_{x z} h(0, b / 2, z)}{q_{0} a}} \\
& =\frac{\tau_{y z} h(a / 2,0, z)}{q_{0} a}, \quad \bar{\sigma}_{z}=\frac{\sigma_{z}(a / 2, b / 2, z)}{q_{0}} \\
\bar{u} & =\frac{E_{2} u(0, b / 2, z)}{h q_{0}} .
\end{aligned}
$$

The percentage difference (PD) in the results are calculated as follows:

$$
\mathrm{PD}=\left[\frac{\text { approximate value }- \text { true value }}{\text { true value }}\right] \times 100
$$

(a) Orthotropic laminate. A simply supported twolayered general cross-ply $(0 / 90)$ square laminate subjected to sinusoidal loading is considered for comparison of displacement and stresses. The following material properties are used here [23]

$$
\begin{aligned}
& E_{1} / E_{2}=25 ; G_{12} / E_{2}=0.50 ; \quad G_{23} / E_{2}=0.20 \\
& E_{2}=E_{3} ; \quad G_{13}=G_{12} ; \quad v_{12}=v_{23}=v_{13}=0.25
\end{aligned}
$$

The results of maximum transverse displacement $\bar{\tau}_{y z} \quad \bar{w}_{0}$, transverse shear and normal stresses are presented in Tables $1-6$ for the two $a / h$ ratios $(a / h=4$ and 10$)$. The variation of maximum transverse displacement $\bar{w}_{0}$ with $a / h$ ratio is shown in Fig. 2 and the variations of transverse shear and normal stresses $\left(\bar{\tau}_{x z}, \bar{\tau}_{y z}, \bar{\sigma}_{z}\right)$ through the laminate thickness are shown in Figs 3-5 for $a / h=4$.

The results show that (Tables 1-6), out of all the models used for evaluation of transverse shear stress $\left(\bar{\tau}_{x z}\right)$, the model HOST7A results are close to the clasticity [23] (-0.260633PD) and closed-form solutions [24] (Fig. 3). But in the case of transverse shear stress $\left(\bar{\tau}_{y z}\right)$, it is seen that model HOST11 gives a

Boundary conditions

These are clearly specified below

$$
\begin{array}{crr}
\text { edge } & \text { simply supported } & \text { symmetry line } \\
\text { At } x=\text { constant } & v_{0}=v_{0}^{*}=w_{0}=w_{0}^{*}=0 & \begin{array}{r}
u_{0}=u_{0}^{*}=0 \\
\theta_{y}=\theta_{y}^{*}=0
\end{array} \\
& \theta_{x}=\theta_{x}^{*}=0 \\
\text { At } y=\text { constant } & u_{0}=u_{0}^{*}=w_{0}=w_{0}^{*}=0 & v_{0}=v_{0}^{*}=0 \\
\theta_{x}=\theta_{x}^{*}=0 & \theta_{y}=\theta_{y}^{*}=0
\end{array}
$$


Table 2. Comparison of transverse shear stress $\left(\bar{\tau}_{\mathrm{yz}}\right)$ for simply supported laminate under sinusoidal loading $(a / h=4)(0 / 90)$ Transverse shear stress $\bar{\tau}_{y=}$

\begin{tabular}{|c|c|c|c|c|c|c|}
\hline \multirow[b]{2}{*}{ Source } & \multirow[b]{2}{*}{ Constitutive } & \multirow{2}{*}{$\begin{array}{c}\text { Direct } \\
\text { integration }\end{array}$} & \multicolumn{2}{|c|}{ Surface fitting methods } & \multicolumn{2}{|c|}{$\begin{array}{c}\text { Direct } \\
\text { difference methods }\end{array}$} \\
\hline & & & diff. & diff. & Forward & Central \\
\hline $\begin{array}{l}\text { HOST7A }(9 \mathrm{~N}) \\
\text { HOST7A }(16 \mathrm{~N})\end{array}$ & $\begin{array}{l}0.2750 \\
0.2750\end{array}$ & $\begin{array}{l}0.29050 \\
0.34900\end{array}$ & $\begin{array}{l}0.293795 \\
0.368240\end{array}$ & $\begin{array}{l}0.293158 \\
0.367645\end{array}$ & $\begin{array}{l}0.294540 \\
0.322775\end{array}$ & $\begin{array}{l}0.293950 \\
0.322195\end{array}$ \\
\hline $\begin{array}{l}\text { HOST7B }(9 N) \\
\text { HOST7B }(16 N)\end{array}$ & $\begin{array}{l}0.2785 \\
0.2117\end{array}$ & $\begin{array}{l}0.29575 \\
0.35450\end{array}$ & $\begin{array}{l}0.302445 \\
0.376105\end{array}$ & $\begin{array}{l}0.298760 \\
0.371475\end{array}$ & $\begin{array}{l}0.303623 \\
0.329635\end{array}$ & $\begin{array}{l}0.299993 \\
0.325538\end{array}$ \\
\hline $\begin{array}{l}\text { HOST }(9 N) \\
\text { HOST } 9(16 N)\end{array}$ & $\begin{array}{l}0.2838 \\
0.2835\end{array}$ & $\begin{array}{l}0.28450 \\
0.34150\end{array}$ & $\begin{array}{l}0.288605 \\
0.360890\end{array}$ & $\begin{array}{l}0.287533 \\
0.359755\end{array}$ & $\begin{array}{l}0.289323 \\
0.316363\end{array}$ & $\begin{array}{l}0.288295 \\
0.315315\end{array}$ \\
\hline $\begin{array}{l}\text { HOST11 (9N) } \\
\text { HOST11 (16N) }\end{array}$ & $\begin{array}{l}0.2768 \\
0.2680\end{array}$ & $\begin{array}{l}0.28375 \\
0.35600\end{array}$ & $\begin{array}{l}0.290025 \\
0.367943\end{array}$ & $\begin{array}{l}0.289123 \\
0.367165\end{array}$ & $\begin{array}{l}0.290443 \\
0.320135\end{array}$ & $\begin{array}{l}0.289590 \\
0.319233\end{array}$ \\
\hline $\begin{array}{l}\text { HOST12 }(9 \mathrm{~N}) \\
\text { HOST12 }(16 \mathrm{~N})\end{array}$ & $\begin{array}{l}0.2808 \\
0.2683\end{array}$ & $\begin{array}{l}0.28400 \\
0.34600\end{array}$ & $\begin{array}{l}0.290318 \\
0.368248\end{array}$ & $\begin{array}{l}0.289443 \\
0.367480\end{array}$ & $\begin{array}{l}0.290718 \\
0.320235\end{array}$ & $\begin{array}{l}0.289885 \\
0.319463\end{array}$ \\
\hline $\begin{array}{l}\text { FOST }(9 N) \\
\text { FOST }(16 N)\end{array}$ & $\begin{array}{l}0.2210 \\
0.2209\end{array}$ & $\begin{array}{l}0.29225 \\
0.35150\end{array}$ & $\begin{array}{l}0.295715 \\
0.371278\end{array}$ & $\begin{array}{l}0.294550 \\
0.370045\end{array}$ & $\begin{array}{l}0.296535 \\
0.325375\end{array}$ & $\begin{array}{l}0.295420 \\
0.324240\end{array}$ \\
\hline Elasticity [23] & & 0.31880 & & & & \\
\hline Ren [24] & & 0.32580 & & & & \\
\hline
\end{tabular}

better estimate of this stress than other models, when compared with elasticity (0.13582PD) and other closed-form solutions (Fig. 4). The sixteen-noded element gives good estimate of the transverse stresses compared to nine-noded element.

In the case of transverse normal stress (Fig. 5), the central difference exact surface fitting method and the direct integration method give almost similar variation through the thickness of the laminate which is slightly different from the elasticity and the CPT results, but it converges to the same value as in elasticity and CPT results at the top and bottom surface of the laminate. Since the elasticity or closed-form solutions are not available for transverse

Table 3. Transverse normal stress $\left(\bar{\sigma}_{z}\right)$ for simply supported laminate under sinusoidal loading (direct integration method) $(a / h=4)(0 / 90)$

\begin{tabular}{ccccccc}
\hline & \multicolumn{5}{c}{ Transverse normal stress $\bar{\sigma}_{z}$ (displacement models) } \\
\cline { 2 - 7 } Thickness & HOST7A & HOST7B & HOST9 & HOST11 & HOST12 & Elasticity [22] \\
\hline-0.5 & 0 & 0 & 0 & 0 & 0 & 0 \\
-0.4 & 0.072450 & 0.071702 & 0.072587 & 0.068390 & 0.068505 & 0.078940 \\
-0.3 & 0.175368 & 0.173535 & 0.175074 & 0.171356 & 0.171758 & 0.250000 \\
-0.2 & 0.289661 & 0.286134 & 0.289113 & 0.287604 & 0.288268 & 0.460526 \\
-0.1 & 0.399147 & 0.393730 & 0.399094 & 0.398570 & 0.399358 & 0.671050 \\
0.0 & 0.489579 & 0.482951 & 0.491027 & 0.487923 & 0.488650 & 0.789474 \\
0.1 & 0.581884 & 0.574045 & 0.584600 & 0.578146 & 0.578746 & 0.868421 \\
0.2 & 0.696006 & 0.687427 & 0.698580 & 0.691239 & 0.691730 & 0.921053 \\
0.3 & 0.816158 & 0.809214 & 0.817625 & 0.811028 & 0.811367 & 0.960526 \\
0.4 & 0.924480 & 0.921438 & 0.924730 & 0.920247 & 0.920384 & 0.973684 \\
0.5 & 1.000000 & 1.000000 & 1.000000 & 1.000000 & 1.000000 & 1.000000 \\
\hline
\end{tabular}

Table 4. Transverse normal stress $\left(\bar{\sigma}_{z}\right)$ for simply supported laminate under sinusoidal loading (central difference exact surface fitting method) $(a / h=4)(0 / 90)$

\begin{tabular}{ccccccc}
\hline & \multicolumn{5}{c}{ Transverse normal stress $\bar{\sigma}_{z}$ (displacement models) } \\
\cline { 2 - 7 } Thickness & HOST7A & HOST7B & HOST9 & HOST11 & HOST12 & CPT [22] \\
\hline-0.5 & 0 & 0 & 0 & 0 & 0 & 0 \\
-0.4 & 0.050674 & 0.054515 & 0.049754 & 0.040865 & 0.040777 & 0.078940 \\
-0.3 & 0.148434 & 0.158050 & 0.146378 & 0.133993 & 0.134141 & 0.263150 \\
-0.2 & 0.268517 & 0.279560 & 0.265800 & 0.252848 & 0.253262 & 0.500000 \\
-0.1 & 0.389826 & 0.397000 & 0.387564 & 0.374165 & 0.374733 & 0.723580 \\
0.0 & 0.493748 & 0.494420 & 0.493407 & 0.477170 & 0.477470 & 0.847368 \\
0.1 & 0.592460 & 0.586593 & 0.594320 & 0.575045 & 0.575550 & 0.921050 \\
0.2 & 0.711721 & 0.701161 & 0.714315 & 0.696275 & 0.696675 & 0.952636 \\
0.3 & 0.833640 & 0.823384 & 0.835752 & 0.821926 & 0.822163 & 0.978947 \\
0.4 & 0.937712 & 0.932668 & 0.938725 & 0.930980 & 0.931029 & 0.989470 \\
0.5 & 1.000000 & 1.000000 & 1.000000 & 1.000000 & 1.000000 & 1.000000 \\
\hline
\end{tabular}


Table 5. Comparison of maximum transverse displacement and transverse shear stress $\left(\bar{\tau}_{x z}\right)$ for simply supported laminate under sinusoidal loading $(a / h=10)(0 / 90)$

\begin{tabular}{|c|c|c|c|c|c|c|c|}
\hline \multirow[b]{3}{*}{ Source } & \multirow[b]{3}{*}{$\bar{w}_{0}$} & \multicolumn{6}{|c|}{ Transverse shear stress $\tilde{t}_{x z}$} \\
\hline & & \multirow[b]{2}{*}{ Constitutive } & \multirow{2}{*}{$\begin{array}{c}\text { Direct } \\
\text { integration }\end{array}$} & \multicolumn{2}{|c|}{ Surface fitting methods } & \multicolumn{2}{|c|}{$\begin{array}{l}\text { Direct difference } \\
\text { methods }\end{array}$} \\
\hline & & & & diff. & diff. & Forward & Central \\
\hline HOST7A $(9 \mathrm{~N})$ & 1.2203 & 0.2564 & 0.2980 & 0.315881 & 0.303760 & 0.313420 & 0.301321 \\
\hline HOST7A $(16 \mathrm{~N})$ & 1.2201 & 0.2565 & 0.3476 & 0.380247 & 0.365304 & 0.336454 & 0.323314 \\
\hline HOST7B (9N) & 1.2128 & 0.2780 & 0.2975 & 0.315874 & 0.303209 & 0.313437 & 0.300749 \\
\hline HOST7B (16N) & 1.2124 & 0.2782 & 0.3476 & 0.380389 & 0.365335 & 0.336571 & 0.323273 \\
\hline HOST9 (9N) & 1.2237 & 0.2728 & 0.2972 & 0.315226 & 0.303227 & 0.312724 & 0.300749 \\
\hline HOST9 (16N) & 1.2236 & 02729 & 0.3463 & 0.378674 & 0.363899 & 0.335126 & 0.322131 \\
\hline HOST11 (9N) & 1.2200 & 0.2735 & 0.2974 & 0.315731 & 0.303784 & 0.313193 & 0.301270 \\
\hline HOSTI1 (16N) & 1.2200 & 0.2736 & 0.3467 & 0.379306 & 0.364467 & 0.336032 & 0.323012 \\
\hline HOST12 $(9 \mathrm{~N})$ & 1.2200 & 0.2735 & 0.2974 & 0.315743 & 0.303795 & 0.313200 & 0.301277 \\
\hline HOST $12(16 \mathrm{~N})$ & 1.2200 & 0.2736 & 0.3467 & 0.379293 & 0.364455 & 0.336026 & 0.323006 \\
\hline FOST (9N) & 1.2378 & 0.2209 & 0.2983 & 0.315853 & 0.304167 & 0.313375 & 0.301710 \\
\hline FOST $(16 N)$ & 1.2377 & 0.2208 & 0.3480 & 0.380177 & 0.365781 & 0.336416 & 0.323752 \\
\hline Elasticity [23] & & & 0.3310 & & & & \\
\hline $\operatorname{Ren}[24]$ & & & 0.3320 & & & & \\
\hline
\end{tabular}

displacement $\bar{w}_{0}$, this has been compared with Mindlin theory for model HOST9 (Fig. 2).

(b) Angle-ply laminate. A two-layered simply supported general angle-ply $\left(15^{\circ} /-15^{\circ}\right)$ square laminate subjected to sinusoidal loading is considered. The following material properties are used [25]

$$
\begin{aligned}
E_{1} / E_{2}=40 ; & G_{12} / E_{2}=0.50 ; \quad G_{23} / E_{2}=0.60 \\
E_{2}=E_{3} ; & G_{13}=G_{12} ; \quad v_{12}=v_{23}=v_{13}=0.25
\end{aligned}
$$

The results of maximum transverse displacement $\bar{w}_{0}$, transverse shear and normal stresses for $a / h=10$ are presented in Tables 7-10. The variation of the maximum transverse displacement $\bar{w}_{0}$ with $a / h$ ratio is shown in Fig. 6 and the variations of transverse shear and normal stresses through the laminate thickness are shown in Figs 7-9 for $a / h=10$.

The results show that the transverse displacement $\tilde{w}_{0}$ obtained by model HOST9 $(9 N)$ is close to closedform solution [25] (-1.5148PD) compared to other models. The classical plate theory underestimates the value and gives a poor estimate for thick laminates (Fig. 6) (-28.0111PD). As the laminate thickness is reduced ( $a / h=50$ and above) all the theories almost give same results, thus showing the validity of the present higher-order theory.

The transverse shear stress $\left(\bar{\tau}_{y z}\right)$ results show that the model HOST9 gives a good estimate of the stress (-0.02158PD) compared to other models. Out of the two elements used, it is seen that sixteen-noded elements give a better estimate of these stresses compared to the other element.

Table 6. Comparison of transverse shear stress $\left(\bar{\tau}_{y z}\right)$ for simply supported laminate under sinusoidal

\begin{tabular}{|c|c|c|c|c|c|c|}
\hline \multirow[b]{3}{*}{ Source } & \multicolumn{6}{|c|}{ Transverse shear stress $\bar{\tau}_{y z}$} \\
\hline & \multirow[b]{2}{*}{ Constitutive } & \multirow{2}{*}{$\begin{array}{c}\text { Direct } \\
\text { integration }\end{array}$} & \multicolumn{2}{|c|}{ Surface fitting methods } & \multicolumn{2}{|c|}{$\begin{array}{l}\text { Direct difference } \\
\text { methods }\end{array}$} \\
\hline & & & diff. & diff. & Forward & Central \\
\hline HOST7A $(9 \mathrm{~N})$ & 0.2811 & 0.2922 & 0.295680 & 0.294610 & 0.296484 & 0.295463 \\
\hline HOST7A (16N) & 0.2811 & 0.3513 & 0.371078 & 0.369960 & 0.325146 & 0.324110 \\
\hline HOST7B (9N) & 0.3178 & 0.2917 & 0.294803 & 0.293813 & 0.295586 & 0.294645 \\
\hline HOST7B $(16 N)$ & 0.3179 & 0.3513 & 0.371053 & 0.369942 & 0.325034 & 0.324020 \\
\hline HOST9 $(9 N)$ & 0.2880 & 0.2914 & 0.295259 & 0.294108 & 0.296050 & 0.294946 \\
\hline HOST9 $(16 N)$ & 0.2881 & 0.3501 & 0.369912 & 0.368695 & 0.324131 & 0.323011 \\
\hline HOST11 (9N) & 0.2816 & 0.2898 & 0.293897 & 0.292744 & 0.294885 & 0.293779 \\
\hline HOST11 (16N) & 0.2869 & 0.3509 & 0.369420 & 0.368222 & 0.306180 & 0.300894 \\
\hline $\operatorname{HOST} 12(9 \mathrm{~N})$ & 0.2868 & 0.2898 & 0.293920 & 0.292768 & 0.294898 & 0.293793 \\
\hline HOST $12(16 N)$ & 0.2869 & 0.3509 & 0.369435 & 0.368238 & 0.323298 & 0.322191 \\
\hline & 0.2209 & 0.2924 & 0.295917 & 0.294750 & 0.296736 & 0.295618 \\
\hline FOST (16N) & 0.2208 & 0.3517 & 0.371634 & 0.370399 & 0.325621 & 0.324483 \\
\hline
\end{tabular}
loading $(a / h=10)(0 / 90)$ 


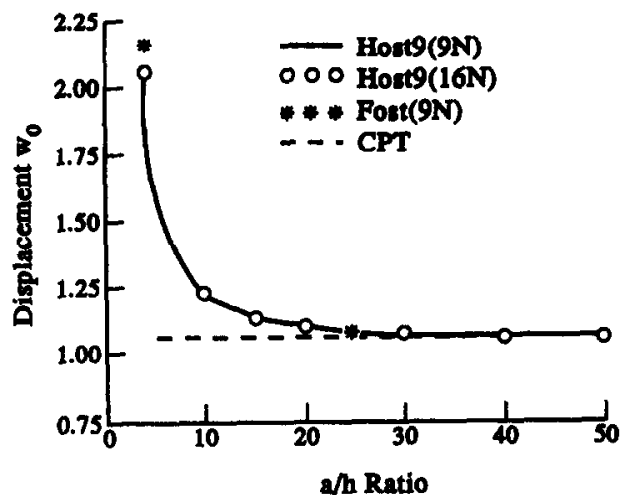

Fig. 2. Convergence of transverse displacement $w_{0}$ with $a / h$ ratio for simply supported laminate under sinusoidal loading $(0 / 90)$

Thus, in Fig. 8, the variation of transverse shear stress obtained by different methods has been shown for the model HOST9. From this figure, it can be seen that direct finite difference method gives good estimate of transverse shear stresses compared to other methods. As the closed-form solutions for transverse shear $\left(\bar{\tau}_{x z}\right)$ and normal stresses are not available, these results are compared with the Reissner/Mindlin theory for model HOST9. These results show that central difference exact surface fitting method gives a much better estimate of the transverse normal stress compared to direct integration method.

(c) Sandwich laminate. A clamped general eightlayered sandwich laminate $\left(0^{\circ} / 45^{\circ} /-45^{\circ} / 30^{\circ} /\right.$ core/ $0^{\circ} / 90^{\circ} / 0^{\circ}$ ) under uniformly distributed loading is considered. The following material properties are used $[28,29]$

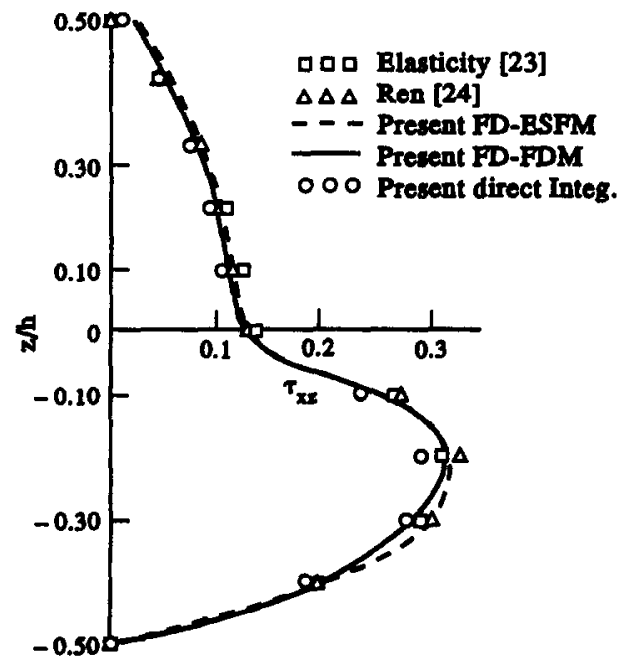

Fig. 3. Variation of transverse shear stress $\left(\tau_{x=}\right)$ through the thickness of a simply supported laminate under sinusoidal loading $(a / h=4)(0 / 90)($ HOST7A)( $9 \mathrm{~N})$.

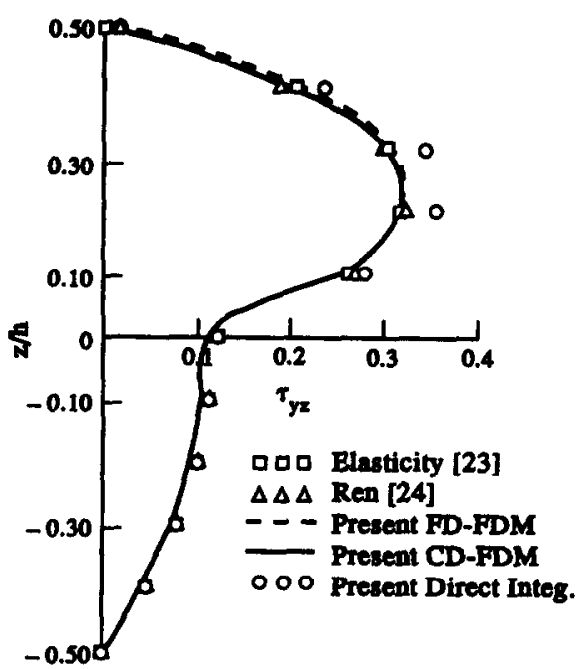

Fig. 4. Variation of transverse shear stress $\left(\tau_{y_{z}}\right)$ through the thickness of a simply supported laminate under sinusoidal loading $(a / h=4)(0 / 90)($ HOST11) $(16 \mathrm{~N})$.

stiff layers

$$
\begin{aligned}
& E_{1}=0.1308 \times 10^{8} \mathrm{psi} ; \quad E_{2}=E_{3}=0.106 \times 10^{7} \mathrm{psi} \\
& G_{12}=G_{13}=0.6 \times 10^{6} \mathrm{psi} ; \quad G_{23}=0.39 \times 10^{6} \mathrm{psi} \\
& v_{12}=v_{13}=0.28 ; \quad v_{23}=0.34
\end{aligned}
$$

core layers

$$
G_{23}=0.1772 \times 10^{5} \mathrm{psi} ; \quad G_{13}=0.5206 \times 10^{5} \mathrm{psi}
$$

$h_{c} / h_{t j}=8 \quad$ [other properties are zero].

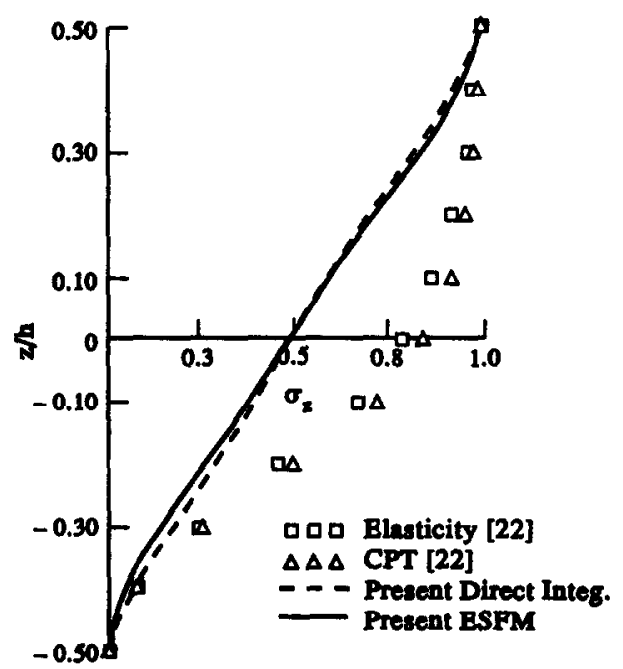

Fig. 5. Variation of transverse normal stress $\left(\sigma_{z}\right)$ through the thickness of a simply supported laminate under sinusoidal loading $(a / h=4)(0 / 90)$ (HOST9) $(16 \mathrm{~N})$. 
Table 7. Comparison of maximum transverse displacement and transverse shear stress $\left(\bar{\tau}_{\mathrm{x} z}\right)$ for simply supported angle-ply laminate under sinusoidal loading $(a / h=10)(15 /-15)$

\begin{tabular}{|c|c|c|c|c|c|c|c|}
\hline \multirow[b]{3}{*}{ Source } & \multirow[b]{3}{*}{$\bar{w}_{0}$} & \multicolumn{6}{|c|}{ Transverse shear stress $\bar{\tau}_{x=}$} \\
\hline & & \multirow[b]{2}{*}{ Constitutive } & \multirow{2}{*}{$\begin{array}{c}\text { Direct } \\
\text { integration }\end{array}$} & \multicolumn{2}{|c|}{ Surface fitting methods } & \multicolumn{2}{|c|}{$\begin{array}{l}\text { Direct difference } \\
\text { methods }\end{array}$} \\
\hline & & & & diff. & diff. & Forward & Central \\
\hline HOST7A (9N) & 0.62360 & 0.2998 & 0.3055 & 0.316829 & 0.307303 & 0.318074 & 0.308574 \\
\hline HOST7A $(16 N)$ & 0.62359 & 0.3001 & 0.3609 & 0.387928 & 0.376566 & 0.345425 & 0.335205 \\
\hline HOST7B $(9 N)$ & 0.61948 & 0.3186 & 0.3044 & 0.316276 & 0.306203 & 0.317491 & 0.307427 \\
\hline HOST7B $(16 N)$ & 0.61951 & 0.3185 & 0.3597 & 0.387345 & 0.375324 & 0.344931 & 0.334120 \\
\hline HOST9 $(9 N)$ & 0.63779 & 0.3036 & 0.3054 & 0.316352 & 0.307223 & 0.318079 & 0.308946 \\
\hline HOST9 (16N) & 0.63774 & 0.3040 & 0.3623 & 0.389425 & 0.378470 & 0.346239 & 0.336357 \\
\hline HOST11 (9N) & 0.63430 & 0.3025 & 0.3039 & 0.314813 & 0.305811 & 0.316312 & 0.307302 \\
\hline HOST11 (16N) & 0.63430 & 0.3018 & 0.3593 & 0.393045 & 0.378470 & 0.343811 & 0.334066 \\
\hline HOST12 $(9 N)$ & 0.63440 & 0.3026 & 0.3039 & 0.314746 & 0.305747 & 0.316283 & 0.307275 \\
\hline HOST12 (16N) & 0.63430 & 0.3019 & 0.3593 & 0.392913 & 0.379935 & 0.343813 & 0.334068 \\
\hline FOST (9N) & 0.63647 & 0.2524 & 0.3068 & 0.317322 & 0.308682 & 0.318566 & 0.309962 \\
\hline FOST (16N) & 0.63646 & 0.2526 & 0.3625 & 0.388543 & 0.378295 & 0.345961 & 0.336727 \\
\hline Ren [25] & 0.64760 & - & - & & & & \\
\hline Turvey [27] & 0.46760 & - & - & & & & \\
\hline CPT [26] & 0.46620 & - & - & & & & \\
\hline
\end{tabular}

Table 8. Comparison of transverse shear stress $\left(\bar{\tau}_{y_{z}}\right)$ for simply supported angle-ply laminate under sinusoidal loading $(a / h=10)(15 /-15)$

\begin{tabular}{|c|c|c|c|c|c|c|}
\hline \multirow[b]{3}{*}{ Source } & \multicolumn{6}{|c|}{ Transverse shear stress $\bar{\tau}_{y z}$} \\
\hline & \multirow[b]{2}{*}{ Constitutive } & \multirow{2}{*}{$\begin{array}{c}\text { Direct } \\
\text { integration }\end{array}$} & \multicolumn{2}{|c|}{ Surface fitting methods } & \multicolumn{2}{|c|}{$\begin{array}{l}\text { Direct difference } \\
\text { methods }\end{array}$} \\
\hline & & & diff. & diff. & Forward & Central \\
\hline HOST7A (9N) & 0.06627 & 0.07483 & 0.078771 & 0.076366 & 0.076027 & 0.073687 \\
\hline HOST7A (16N) & 0.06083 & 0.08017 & 0.084976 & 0.082348 & 0.078247 & 0.075816 \\
\hline $\operatorname{HOST7B}(9 \mathrm{~N})$ & 0.07097 & 0.07453 & 0.075807 & 0.076039 & 0.075779 & 0.073372 \\
\hline HOST7B (16N) & 0.07062 & 0.07995 & 0.084835 & 0.082100 & 0.078125 & 0.075592 \\
\hline HOST9 $(9 N)$ & 0.06983 & 0.07347 & 0.077283 & 0.075070 & 0.074462 & 0.072313 \\
\hline HOST9 $(16 N)$ & 0.06958 & 0.07833 & 0.082808 & 0.080420 & 0.076365 & 0.074146 \\
\hline HOST11 (9N) & 0.06633 & 0.07386 & 0.077656 & 0.075446 & 0.074765 & 0.072624 \\
\hline HOSTI $1(16 N)$ & 0.06941 & 0.07836 & 0.082924 & 0.080520 & 0.076598 & 0.074368 \\
\hline HOST12 (9N) & 0.06633 & 0.07386 & 0.077645 & 0.075435 & 0.074765 & 0.072624 \\
\hline HOST12 (16N) & 0.06502 & 0.07832 & 0.082874 & 0.080474 & 0.076578 & 0.074349 \\
\hline FOST $(9 N)$ & 0.05652 & 0.07538 & 0.079200 & 0.076944 & 0.076453 & 0.074255 \\
\hline FOST (16N) & 0.05629 & 0.08083 & 0.085533 & 0.083055 & 0.078724 & 0.076538 \\
\hline $\operatorname{Ren}[25]$ & & 0.07413 & & & & \\
\hline
\end{tabular}

Table 9. Transverse normal stress $\left(\bar{\sigma}_{z}\right)$ for simply supported angle-ply laminate under sinusoidal loading (direct integration method) $(a / h=10)(15 /-15)$

\begin{tabular}{ccccccc}
\hline & \multicolumn{5}{c}{ Transverse normal stress $\bar{\sigma}_{z}$ (displacement models) } \\
\cline { 2 - 7 } Thickness & HOST7A & HOST7B & HOST9 & HOST11 & HOST12 & FOST \\
\hline-0.5 & 0 & 0 & 0 & 0 & 0 & 0 \\
-0.4 & 0.064180 & 0.066407 & 0.061398 & 0.062888 & 0.062887 & 0.061493 \\
-0.3 & 0.185102 & 0.190181 & 0.178793 & 0.180703 & 0.180740 & 0.178978 \\
-0.2 & 0.334033 & 0.340720 & 0.324729 & 0.326901 & 0.326980 & 0.326312 \\
-0.1 & 0.484538 & 0.491339 & 0.473509 & 0.476119 & 0.476238 & 0.477349 \\
0.0 & 0.611708 & 0.617966 & 0.600413 & 0.603598 & 0.603774 & 0.605944 \\
0.1 & 0.708096 & 0.714068 & 0.697938 & 0.701466 & 0.701678 & 0.703392 \\
0.2 & 0.787364 & 0.792734 & 0.779724 & 0.783140 & 0.783325 & 0.783661 \\
0.3 & 0.857099 & 0.860976 & 0.852794 & 0.852794 & 0.855626 & 0.854610 \\
0.4 & 0.925194 & 0.926854 & 0.923963 & 0.925685 & 0.925721 & 0.924103 \\
0.5 & 1.000000 & 1.000000 & 1.000000 & 1.000000 & 1.000000 & 1.000000 \\
\hline
\end{tabular}


Table 10. Transverse normal stress $\left(\bar{\sigma}_{z}\right)$ for simply supported angle-ply laminate under sinusoidal loading (central difference exact surface fitting method) $(a / h=10)(15 /-15)$

\begin{tabular}{ccccccc}
\hline & \multicolumn{5}{c}{ Transverse normal stress $\bar{\sigma}_{z}$ (displacement models) } \\
\cline { 2 - 7 } Thickness & HOST7A & HOST7B & HOST9 & HOST11 & HOST12 & FOST \\
\hline-0.5 & 0 & 0 & 0 & 0 & 0 & 0 \\
-0.4 & 0.046765 & 0.047343 & 0.046776 & 0.047250 & 0.047250 & 0.045767 \\
-0.3 & 0.138376 & 0.139929 & 0.137452 & 0.137947 & 0.137977 & 0.135768 \\
-0.2 & 0.253995 & 0.255835 & 0.252429 & 0.253302 & 0.253343 & 0.250970 \\
-0.1 & 0.374325 & 0.375566 & 0.373186 & 0.374740 & 0.374771 & 0.372341 \\
0.0 & 0.481108 & 0.481269 & 0.481767 & 0.483730 & 0.483758 & 0.480850 \\
0.1 & 0.584960 & 0.584001 & 0.587567 & 0.589245 & 0.589284 & 0.586451 \\
0.2 & 0.708632 & 0.706888 & 0.711581 & 0.712717 & 0.712757 & 0.711448 \\
0.3 & 0.832948 & 0.831281 & 0.834912 & 0.835578 & 0.835600 & 0.835704 \\
0.4 & 0.937403 & 0.936627 & 0.937914 & 0.938286 & 0.938284 & 0.938721 \\
0.5 & 1.000000 & 1.000000 & 1.000000 & 1.000000 & 1.000000 & 1.000000 \\
\hline
\end{tabular}

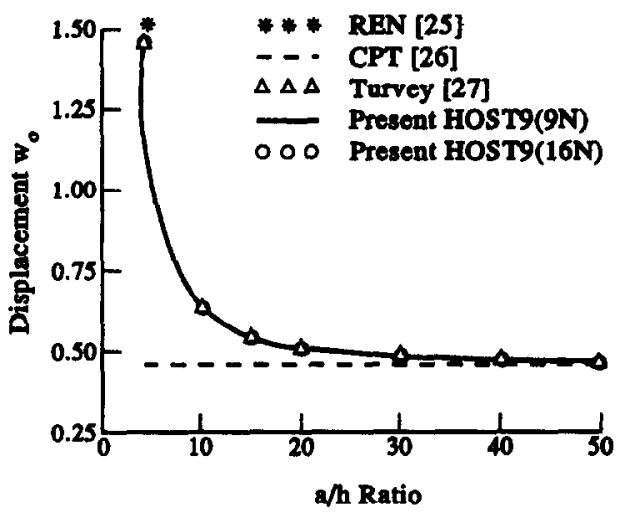

Fig. 6. Convergence of transverse displacement $w_{0}$ with $a / h$ ratio for simply supported angle-ply laminate under sinusoidal loading $(15 /-15)$.

The results of maximum transverse displacement $\bar{w}_{0}$, transverse shear and normal stresses are presented in Tables $11-16$ for $a / h=10$ and 50 . The variations of transverse shear stresses $\left(\bar{\tau}_{x z}, \bar{t}_{y z}\right)$, transverse normal stress $\left(\tilde{\sigma}_{z}\right)$ and in-plane displacement through the

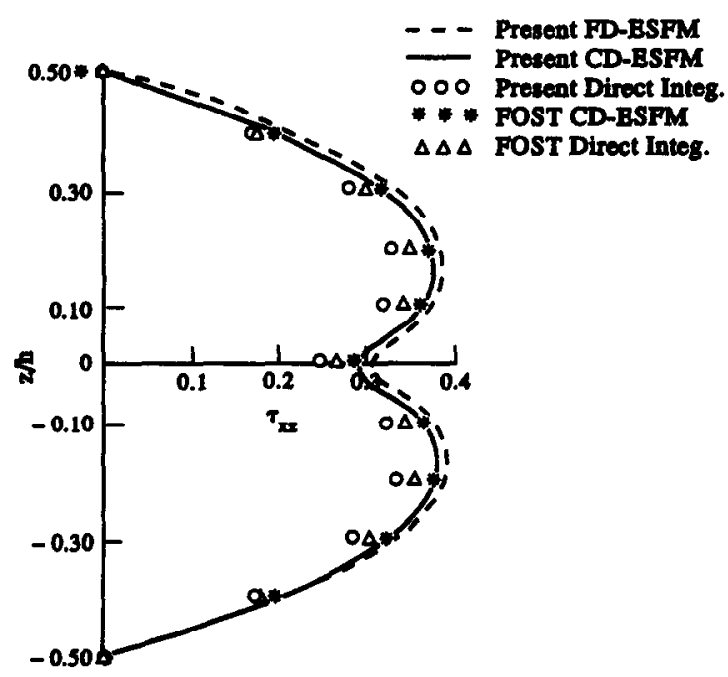

Fig. 7. Variation of transverse shear stress $\left(\tau_{x z}\right)$ through the thickness of a simply supported angle-ply laminate under sinusoidal loading $(a / h=10)(15 /-15)($ HOST9) $(16 \mathrm{~N})$.

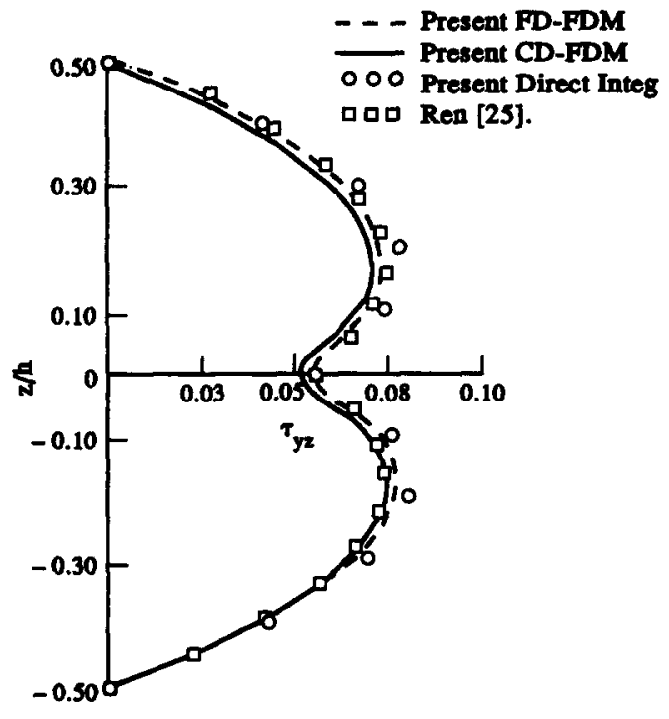

Fig. 8. Variation of transverse shear stress $\left(\tau_{y z}\right)$ through the thickness of a simply supported angle-ply laminate under sinusoidal loading $(a / h=10)(15 /-15)$ (HOST9)(16N).

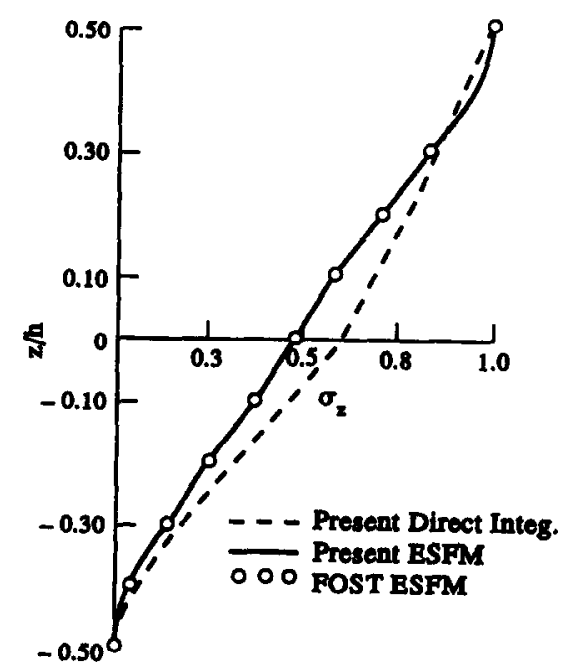

Fig. 9. Variation of transverse normal stress $\left(\sigma_{z}\right)$ through the thickness of a simply supported angle-ply laminate under sinusoidal loading $(a / h=10)(15 /-15)$ (HOST9) $(16 \mathrm{~N})$. 
Table 11. Comparison of maximum transverse displacement and transverse shear stress $\left(\bar{\tau}_{x z}\right)$ for clamped general sandwich laminate under uniformly distributed loading $(a / h=10)(0 / 45 /-45 / 30 /$ core/30/90/0)

\begin{tabular}{|c|c|c|c|c|c|c|c|}
\hline \multirow[b]{3}{*}{ Source } & \multirow[b]{3}{*}{$\bar{w}_{0}$} & \multicolumn{6}{|c|}{ Transverse shear stress $\bar{\tau}_{x z}$} \\
\hline & & \multirow[b]{2}{*}{ Constitutive } & \multirow{2}{*}{$\begin{array}{c}\text { Direct } \\
\text { integration }\end{array}$} & \multicolumn{2}{|c|}{ Surface fitting methods } & \multicolumn{2}{|c|}{$\begin{array}{l}\text { Direct difference } \\
\text { methods }\end{array}$} \\
\hline & & & & diff. & diff. & Forward & Central \\
\hline HOST7A (9N) & 2.21540 & 0.10240 & 0.3821 & 0.412020 & 0.391712 & 0.404891 & 0.384793 \\
\hline HOST7A $(16 N)$ & 1.88489 & 0.10030 & 0.3965 & 0.430220 & 0.410952 & 0.370800 & 0.355310 \\
\hline HOST7B (9N) & 1.81536 & 0.09762 & 0.3279 & 0.348582 & 0.334808 & 0.342354 & 0.328515 \\
\hline HOST7B (16N) & 1.92189 & 0.09556 & 0.3449 & 0.372943 & 0.358484 & 0.340535 & 0.329518 \\
\hline HOST9 $(9 N)$ & 2.26427 & 0.12260 & 0.3929 & 0.424156 & 0.402516 & 0.416522 & 0.395107 \\
\hline HOST9 (16N) & 1.92581 & 0.12320 & 0.4083 & 0.443873 & 0.422986 & 0.381884 & 0.365075 \\
\hline HOST11 (9N) & 2.25568 & 0.12540 & 0.3884 & 0.418365 & 0.396700 & 0.413275 & 0.391924 \\
\hline HOST11 (16N) & 1.92390 & 0.11271 & 0.4050 & 0.438911 & 0.417986 & 0.380258 & 0.363431 \\
\hline $\operatorname{HOST} 12(9 \mathrm{~N})$ & 2.27158 & 0.13780 & 0.3754 & 0.405076 & 0.385445 & 0.393505 & 0.374439 \\
\hline HOST12 (16N) & 1.93026 & 0.13800 & 0.4050 & 0.441727 & 0.421482 & 0.378987 & 0.362909 \\
\hline FOST $(9 N)$ & 1.20586 & 0.10880 & 0.3297 & 0.343860 & 0.336622 & 0.333840 & 0.326624 \\
\hline FOST (16N) & 1.20193 & 0.10780 & 0.3415 & 0.363291 & 0.354409 & 0.332340 & 0.324794 \\
\hline
\end{tabular}

Table 12. Comparison of transverse shear stress $\left(\bar{\tau}_{y z}\right)$ for clamped general sandwich laminate under uniformly distributed loading $(a / h=10)(0 / 45 /-45 / 30 /$ core $/ 30 / 90 / 0)$

\begin{tabular}{|c|c|c|c|c|c|c|}
\hline \multirow[b]{3}{*}{ Source } & \multicolumn{6}{|c|}{ Transverse shear stress $\bar{\tau}_{y=}$} \\
\hline & \multirow[b]{2}{*}{ Constitutive } & \multirow{2}{*}{$\begin{array}{c}\text { Direct } \\
\text { integration }\end{array}$} & \multicolumn{2}{|c|}{ Surface fitting methods } & \multicolumn{2}{|c|}{$\begin{array}{l}\text { Direct difference } \\
\text { methods }\end{array}$} \\
\hline & & & diff. & diff. & Forward & Central \\
\hline HOST7A (9N) & 0.07191 & 0.19060 & 0.197163 & 0.194537 & 0.192243 & 0.189660 \\
\hline HOST7A (16N) & 0.03243 & 0.21130 & 0.230643 & 0.227588 & 0.192959 & 0.190494 \\
\hline HOST7B $(9 N)$ & 0.03528 & 0.22490 & 0.234654 & 0.233014 & 0.226215 & 0.224599 \\
\hline HOST7B $(16 N)$ & 0.03487 & 0.24770 & 0.266756 & 0.265128 & 0.226008 & 0.224582 \\
\hline HOST9 $(9 N)$ & 0.04469 & 0.19340 & 0.200892 & 0.197583 & 0.195567 & 0.192269 \\
\hline HOST9 $(16 N)$ & 0.04364 & 0.20910 & 0.229725 & 0.226161 & 0.190678 & 0.187909 \\
\hline HOST11 (9N) & 0.04524 & 0.19470 & 0.203255 & 0.199490 & 0.198053 & 0.194291 \\
\hline HOST11 (16N) & 0.04455 & 0.20580 & 0.225372 & 0.221257 & 0.188731 & 0.185588 \\
\hline HOST12 (9N) & 0.04846 & 0.20170 & 0.216290 & 0.211936 & 0.202786 & 0.198791 \\
\hline HOST12 (16N) & 0.04815 & 0.21470 & 0.234758 & 0.231736 & 0.190630 & 0.188495 \\
\hline FOST $(9 N)$ & 0.03691 & 0.24890 & 0.255624 & 0.254392 & 0.245254 & 0.244044 \\
\hline FOST $(16 N)$ & 0.03641 & 0.26770 & 0.282116 & 0.280673 & 0.243843 & 0.242606 \\
\hline
\end{tabular}

laminate thickness are shown in Figs 10-13 for $a / h=10$. As the elasticity and other closed-form solutions are not available for this problem, the results have been compared with Reissner/Mindlin theory.
A comparison of maximum transverse displacement $\bar{w}_{0}(-46.74398 \mathrm{PD})$ and transverse shear $\left(-16.21259 \mathrm{PD}\right.$ for $\bar{\tau}_{x z}$ and $-24.10318 \mathrm{PD}$ for $\left.\bar{\tau}_{y z}\right)$ and normal stresses show a large difference between the results of present higher-order theory (HOST9) $(16 \mathrm{~N})$

Table 13. Transverse normal stress $\left(\bar{\sigma}_{z}\right)$ for clamped general sandwich laminate uniformly distributed loading (direct integration method) $(a / h=10)(0 / 45 /-45 / 30 /$ core $/ 30 / 90 / 0)$

\begin{tabular}{ccccccc}
\hline & \multicolumn{5}{c}{ Transverse normal stress $\bar{\sigma}_{z}$ (displacement models) } \\
\cline { 2 - 7 } Thickness & HOST7A & HOST7B & HOST9 & HOST11 & HOST12 & FOST \\
\hline-0.50 & 0 & 0 & 0 & 0 & 0 & 0 \\
-0.46 & 0.253412 & 0.120091 & 0.345277 & 0.311682 & 0.154449 & 0.012800 \\
-0.42 & 0.304468 & 0.122620 & 0.515862 & 0.442858 & 0.365606 & -0.074818 \\
-0.38 & 0.342245 & 0.177984 & 0.581164 & 0.482060 & 0.469585 & -0.038654 \\
-0.34 & 0.497789 & 0.273473 & 0.858696 & 0.724058 & 0.723075 & -0.043678 \\
0.41 & 0.290064 & 0.821224 & 0.595232 & 0.416973 & 0.268363 & 1.249890 \\
0.44 & 0.446190 & 0.918987 & 0.646431 & 0.530174 & 0.320487 & 1.178470 \\
0.47 & 0.834263 & 0.944653 & 0.911620 & 0.849561 & 0.737319 & 1.093010 \\
0.50 & 1.000000 & 1.000000 & 1.000000 & 1.000000 & 1.000000 & 1.000000 \\
\hline
\end{tabular}


Table 14. Transverse normal stress $\left(\delta_{z}\right)$ for clamped general sandwich laminate uniformly distributed loading (central difference exact surface fitting method) $(a / h=10)(0 / 45 /-45 / 30 / c 0 r e / 30 / 90 / 0)$

\begin{tabular}{ccccccc}
\hline & \multicolumn{5}{c}{ Transverse normal stress $\sigma_{z}$ (displacement models) } \\
\cline { 2 - 7 } Thickness & HOST7A & HOST7B & HOST9 & HOST11 & HOST12 & FOST \\
\hline-0.50 & 0 & 0 & 0 & 0 & 0 & 0 \\
-0.46 & 0.085398 & 0.087944 & 0.103682 & 0.089628 & 0.106582 & 0.018231 \\
-0.42 & 0.204132 & 0.203720 & 0.243022 & 0.216715 & 0.247263 & 0.057263 \\
-0.38 & 0.339203 & 0.338140 & 0.398867 & 0.361769 & 0.406251 & 0.116415 \\
-0.34 & 0.478337 & 0.480593 & 0.556702 & 0.510081 & 0.569144 & 0.192099 \\
0.41 & 0.622189 & 0.624164 & 0.684619 & 0.642993 & 0.692596 & 0.404741 \\
0.44 & 0.760971 & 0.762994 & 0.802725 & 0.771268 & 0.806239 & 0.620268 \\
0.47 & 0.890262 & 0.890873 & 0.910865 & 0.893421 & 0.911901 & 0.819961 \\
0.50 & 1.000000 & 1.000000 & 1.000000 & 1.000000 & 1.000000 & 1.000000 \\
\hline
\end{tabular}

Table 15. Comparison of maximum transverse displacement and transverse shear stress $\left(\bar{\tau}_{x z}\right)$ for clamped general sandwich laminate under uniformly distributed loading $(a / h=50)(0 / 45 /-45 / 30 /$ core/30/90/0)

\begin{tabular}{|c|c|c|c|c|c|c|c|}
\hline \multirow[b]{3}{*}{ Source } & \multirow[b]{3}{*}{$\bar{w}_{0}$} & \multicolumn{6}{|c|}{ Transverse shear stress $\bar{\tau}_{x z}$} \\
\hline & & \multirow[b]{2}{*}{ Constitutive } & \multirow{2}{*}{$\begin{array}{c}\text { Direct } \\
\text { integration }\end{array}$} & \multirow{2}{*}{\multicolumn{2}{|c|}{$\begin{array}{cc}\text { Surface fitting methods } \\
\begin{array}{c}\text { Forward } \\
\text { diff. }\end{array} & \text { Central } \\
\text { diff. }\end{array}$}} & \multicolumn{2}{|c|}{$\begin{array}{c}\text { Direct difference } \\
\text { methods }\end{array}$} \\
\hline & & & & & & Forward & Central \\
\hline $\begin{array}{l}\text { HOST7A (9N) } \\
\text { HOST7A (16N) }\end{array}$ & $\begin{array}{l}0.62662 \\
0.59857\end{array}$ & $\begin{array}{l}0.10256 \\
0.10606\end{array}$ & $\begin{array}{l}0.3524 \\
0.3888\end{array}$ & $\begin{array}{l}0.362388 \\
0.411172\end{array}$ & $\begin{array}{l}0.353498 \\
0.400344\end{array}$ & $\begin{array}{l}0.355146 \\
0.360626\end{array}$ & $\begin{array}{l}0.346266 \\
0.351558\end{array}$ \\
\hline $\begin{array}{l}\operatorname{HOST7B}(9 N) \\
\text { HOST7B }(16 N)\end{array}$ & $\begin{array}{l}0.60301 \\
0.59950\end{array}$ & $\begin{array}{l}0.10668 \\
0.10876\end{array}$ & $\begin{array}{l}0.3504 \\
0.3836\end{array}$ & $\begin{array}{l}0.358934 \\
0.406526\end{array}$ & $\begin{array}{l}0.350516 \\
0.396038\end{array}$ & $\begin{array}{l}0.352030 \\
0.357104\end{array}$ & $\begin{array}{l}0.343620 \\
0.348314\end{array}$ \\
\hline $\begin{array}{l}\text { HOST9 }(9 N) \\
\text { HOST9 }(16 N)\end{array}$ & $\begin{array}{l}0.62990 \\
0.60059\end{array}$ & $\begin{array}{l}0.13594 \\
0.13544\end{array}$ & $\begin{array}{l}0.3524 \\
0.3890\end{array}$ & $\begin{array}{l}0.362790 \\
0.411410\end{array}$ & $\begin{array}{l}0.353800 \\
0.400508\end{array}$ & $\begin{array}{l}0.355496 \\
0.360936\end{array}$ & $\begin{array}{l}0.346520 \\
0.351808\end{array}$ \\
\hline $\begin{array}{l}\text { HOST11 }(9 \mathrm{~N}) \\
\text { HOST11 }(16 \mathrm{~N})\end{array}$ & $\begin{array}{l}0.62684 \\
0.59750\end{array}$ & $\begin{array}{l}0.13706 \\
0.13676\end{array}$ & $\begin{array}{l}0.3596 \\
0.3956\end{array}$ & $\begin{array}{l}0.372296 \\
0.421338\end{array}$ & $\begin{array}{l}0.363166 \\
0.410338\end{array}$ & $\begin{array}{l}0.360222 \\
0.364406\end{array}$ & $\begin{array}{l}0.351188 \\
0.355268\end{array}$ \\
\hline $\begin{array}{l}\text { HOST12 }(9 \mathrm{~N}) \\
\text { HOST12 }(16 \mathrm{~N})\end{array}$ & $\begin{array}{l}0.62684 \\
0.59750\end{array}$ & $\begin{array}{l}0.13888 \\
0.13902\end{array}$ & $\begin{array}{l}0.3596 \\
0.3956\end{array}$ & $\begin{array}{l}0.372344 \\
0.401370\end{array}$ & $\begin{array}{l}0.363154 \\
0.410304\end{array}$ & $\begin{array}{l}0.360222 \\
0.364422\end{array}$ & $\begin{array}{l}0.351172 \\
0.355256\end{array}$ \\
\hline $\begin{array}{l}\text { FOST }(9 N) \\
\text { FOST }(16 N)\end{array}$ & $\begin{array}{l}0.57508 \\
0.56766\end{array}$ & $\begin{array}{l}0.12068 \\
0.12394\end{array}$ & $\begin{array}{l}0.3498 \\
0.3866\end{array}$ & $\begin{array}{l}0.356864 \\
0.407498\end{array}$ & $\begin{array}{l}0.348728 \\
0.397234\end{array}$ & $\begin{array}{l}0.350380 \\
0.355806\end{array}$ & $\begin{array}{l}0.342250 \\
0.347196\end{array}$ \\
\hline
\end{tabular}

and the Reissner/Mindlin theory for thick sandwich laminates $(a / h \leqslant 10)$. The error is due to the simplifying assumptions made in the Reissner/Mindlin theory. As the laminate thickness is reduced, it is seen that the discrepancy between the present theory and the Reissner/Mindlin theory decreases and for very thin laminates $(a / h \geqslant 50)$, the results of both the theories converge to the same value $\left(-8.70297 \mathrm{PD}\right.$ for $\bar{w}_{0}$ and $-0.81746 \mathrm{PD}$ for $\bar{\tau}_{x z}$ ).

Table 16. Comparison of transverse shear stress $\left(\bar{i}_{y z}\right)$ for clamped general sandwich laminate under uniformly distributed loading $(a / h=50)(0 / 45 /-45 / 30 /$ core $/ 30 / 90 / 0)$

\begin{tabular}{|c|c|c|c|c|c|c|}
\hline \multirow[b]{3}{*}{ Source } & \multicolumn{6}{|c|}{ Transverse shear stress $\bar{\tau}_{y z}$} \\
\hline & \multirow[b]{2}{*}{ Constitutive } & \multirow{2}{*}{$\begin{array}{c}\text { Direct } \\
\text { integration }\end{array}$} & \multirow{2}{*}{\multicolumn{2}{|c|}{$\begin{array}{l}\text { Surface fitting methods } \\
\text { Forward } \\
\text { diff. }\end{array}$}} & \multicolumn{2}{|c|}{$\begin{array}{l}\text { Direct difference } \\
\text { methods }\end{array}$} \\
\hline & & & & & Forward & Central \\
\hline $\begin{array}{l}\text { HOST7A }(9 N) \\
\text { HOST7A }(16 N)\end{array}$ & $\begin{array}{l}0.04570 \\
0.04548\end{array}$ & $\begin{array}{l}0.2432 \\
0.2692\end{array}$ & $\begin{array}{l}0.243496 \\
0.281160\end{array}$ & $\begin{array}{l}0.242154 \\
0.279576\end{array}$ & $\begin{array}{l}0.237242 \\
0.237432\end{array}$ & $\begin{array}{l}0.235908 \\
0.236114\end{array}$ \\
\hline $\begin{array}{l}\operatorname{HOST7B}(9 N) \\
\text { HOST7B }(16 N)\end{array}$ & $\begin{array}{l}0.04324 \\
0.04398\end{array}$ & $\begin{array}{l}0.2500 \\
0.2772\end{array}$ & $\begin{array}{l}0.249488 \\
0.289012\end{array}$ & $\begin{array}{l}0.248230 \\
0.287490\end{array}$ & $\begin{array}{l}0.243034 \\
0.243248\end{array}$ & $\begin{array}{l}0.241784 \\
0.241974\end{array}$ \\
\hline $\begin{array}{l}\text { HOST9 }(9 \mathrm{~N}) \\
\text { HOST9 }(16 \mathrm{~N})\end{array}$ & $\begin{array}{l}0.06667 \\
0.06346\end{array}$ & $\begin{array}{l}0.2422 \\
0.2680\end{array}$ & $\begin{array}{l}0.242710 \\
0.280242\end{array}$ & $\begin{array}{l}0.241350 \\
0.278644\end{array}$ & $\begin{array}{l}0.236468 \\
0.236728\end{array}$ & $\begin{array}{l}0.235116 \\
0.235402\end{array}$ \\
\hline $\begin{array}{l}\text { HOST11 (9N) } \\
\text { HOST11 (16N) }\end{array}$ & $\begin{array}{l}0.06684 \\
0.06372\end{array}$ & $\begin{array}{l}0.2534 \\
0.2780\end{array}$ & $\begin{array}{l}0.257768 \\
0.294420\end{array}$ & $\begin{array}{l}0.256116 \\
0.292546\end{array}$ & $\begin{array}{l}0.244336 \\
0.242052\end{array}$ & $\begin{array}{l}0.242798 \\
0.240594\end{array}$ \\
\hline $\begin{array}{l}\text { HOST12 }(9 \mathrm{~N}) \\
\text { HOST12 (16N) }\end{array}$ & $\begin{array}{l}0.06746 \\
0.06446\end{array}$ & $\begin{array}{l}0.2534 \\
0.2780\end{array}$ & $\begin{array}{l}0.257768 \\
0.294408\end{array}$ & $\begin{array}{l}0.256056 \\
0.292474\end{array}$ & $\begin{array}{l}0.244336 \\
0.242052\end{array}$ & $\begin{array}{l}0.242756 \\
0.240570\end{array}$ \\
\hline $\begin{array}{l}\text { FOST }(9 N) \\
\text { FOST }(16 N)\end{array}$ & $\begin{array}{l}0.04098 \\
0.04198\end{array}$ & $\begin{array}{l}0.2530 \\
0.2842\end{array}$ & $\begin{array}{l}0.251250 \\
0.293978\end{array}$ & $\begin{array}{l}0.250008 \\
0.292448\end{array}$ & $\begin{array}{l}0.245086 \\
0.246078\end{array}$ & $\begin{array}{l}0.243850 \\
0.244802\end{array}$ \\
\hline
\end{tabular}




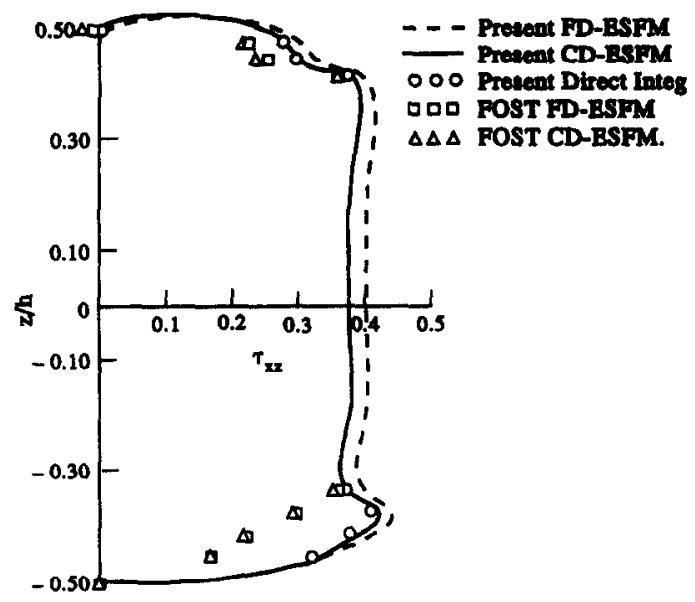

Fig. 10. Variation of transverse shear stress $\left(\tau_{x z}\right)$ through the thickness of a clamped general sandwich laminate under uniformly distributed loading $(a / h=10)$ (HOST9) $(16 \mathrm{~N})$.

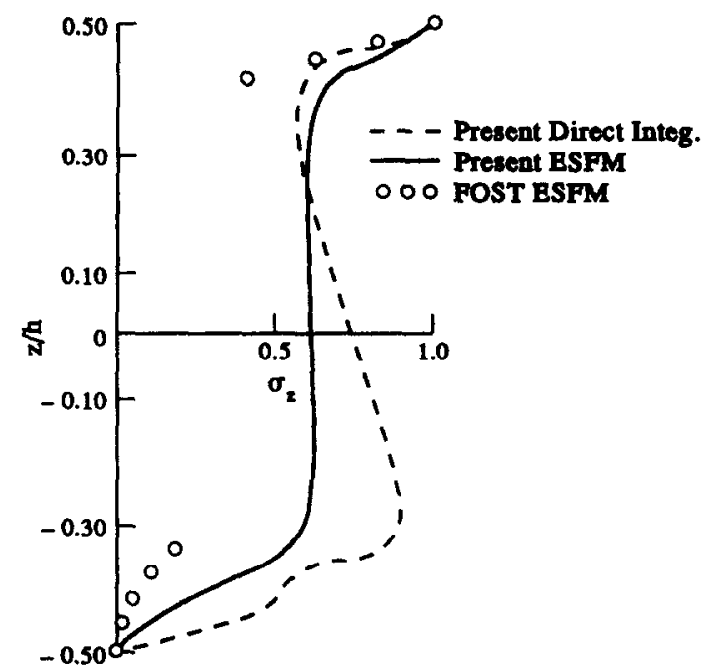

Fig. 12. Variation of transverse normal stress $\left(\sigma_{z}\right)$ through the thickness of a clamped general sandwich laminate under uniformly distributed loading $(a / h=10)$ (HOST9)(16N).

The transverse normal stress variation distinctly shows the difference between the present higher-order theory and the Reissner/Mindlin theory (Fig. 12). As seen in previous problems, here also the exact surface fitting method gives a good estimate of the stress compared to the direct integration method. The in-plane displacement variation clearly brings out the realistic cubic variation of the cross-section of the laminate for model HOST9 (Fig. 13). But the Reissner/Mindlin theory gives an unrealistic straight line variation through the thickness of the laminate.

\section{CONCLUSIONS}

It has been demonstrated in this paper that the versatile finite element analysis of the $C^{0}$ higher-order theories can accurately predict the complex transverse stresses and deformation behaviour of composite and sandwich laminates subjected to a variety of loadings.

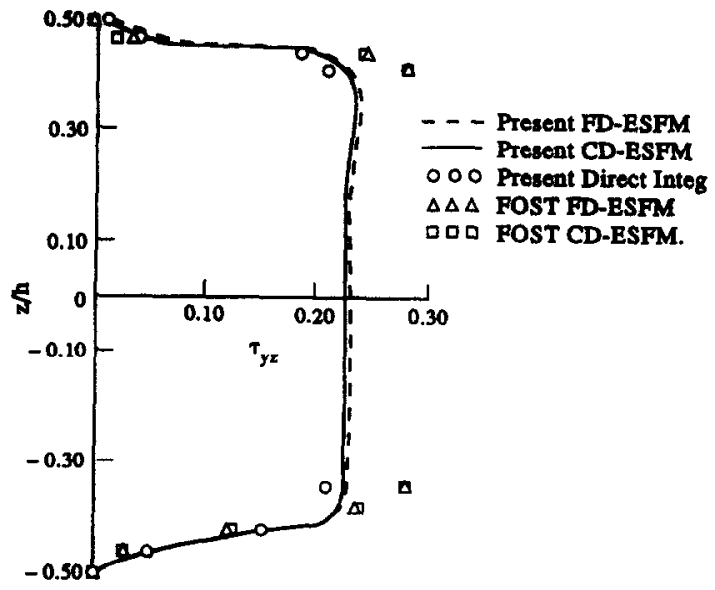

Fig. 11. Variation of transverse shear stress $\left(\tau_{y z}\right)$ through the thickness of a clamped general sandwich laminate under uniformly distributed loading ( $a / h=10)$ (HOST9)(16N).

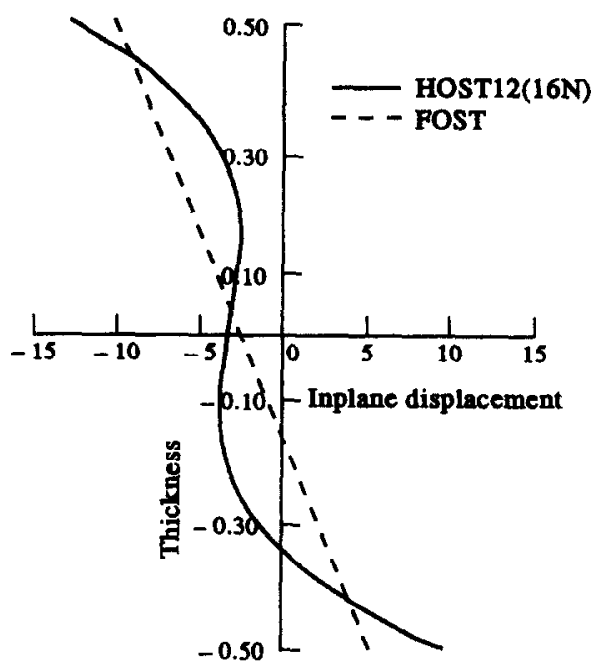

Fig. 13. Variation of in-plane displacement through the thickness of a clamped general sandwich laminate under uniformly distributed loading $(a / h=10)($ HOST9) $(16 \mathrm{~N})$.

These theories assume the realistic non-linear variation of displacements. The numerical results for displacement and transverse stresses when compared with the available elasticity and other closed-form solutions show good agreement. The convergence has been demonstrated in all cases in the limit when $a / h$ ratio tends to be large. The results obtained by models when zero top and bottom shear conditions are not enforced are close to the elasticity and other closedform solutions compared to the models when this condition is enforced especially for thick laminates.

The delamination stress evaluation using the finite element method under any type of loading conditions is not going to be a simple job in composite and sandwich laminates. This is due to the higher-order numerical differentiation (third derivative) in the longitudinal direction associated with the integration of the elasticity equilibrium equations in the thickness direction. The use of the proposed new methods and 
cubic $C^{0}$ elements seems to have given fairly accurate estimates of these stresses.

The proposed exact surface fitting method can be efficiently employed for evaluating the transverse shear stresses and central difference exact surface fitting method is recommended for evaluation of transverse normal stress. The results obtained by these methods are close to the available closed-form elasticity solution when compared to direct integration and finite difference methods. The results of transverse shear and normal stresses are also presented for new problems where elasticity solutions are not available with a view to provide data for future reference.

The displacements and transverse stresses obtained by model HOST9 (nine degrees of freedom per node) are close to the closed-form elasticity solutions compared to the other models. Thus, this model is recommended for general composite laminates. But for sandwich and highly anisotropic composite laminate, model HOST12 is recommended as this model considers the three-dimensional material properties and non-linear variation of transverse displacement through the thickness of the laminate.

Acknowledgement-Partial support of this research by the Aeronautics Research and Development Board, Ministry of Defence, Government of India through its Grants Aero/RD-134/100/10/88-89/534 is gratefully acknowledged.

\section{REFERENCES}

1. R. M. Jones, Mechanics of Composite Materials. McGraw-Hill, New York (1975).

2. E. Reissner, The effect of transverse shear deformation on the bending of elastic plates. ASME J. Appl. Mech. 12, A69-A77 (1945).

3. R. D. Mindlin, Influence of rotatory inertia and shear deformation on flexural motions of isotropic elastic plates. ASME J. Appl. Mech. 18, 31-38 (1951).

4. E. Reissner, On transverse bending of plates, including the effect of transverse shear deformation. Int. J. Solids Struct. 11, 569-573 (1975).

5. K. H. Lo, R. M. Christensen and E. M. Wu, A high order theory of plate deformation-Part 2: Laminated plates. ASME J. Appl. Mech. 44, 669-676 (1977).

6. K. H. Lo, R. M. Christensen and E. M. Wu, Stress solution determination for high order plate theory. Int. J. Solids Struct. 14, 655-662 (1978).

7. T. Kant, Numerical analysis of thick plates. Comput. Meth. appl. Mech. Engng 31, 1-18 (1982).

8. T. Kant, D. R. J. Owen and O. C. Zienkiewicz, A refined higher-order $C^{0}$ plate bending element. Comput. Struct. 15, 177-183 (1982).

9. B. N. Pandya and T. Kant, Finite element stress analysis of laminated composite plates using a higher-order displacement model. Compos. Sci. Technol. 32, 137-155 (1988).

10. B. N. Pandya and T. Kant, A simple finite element formulation of a higher-order theory for unsymmetri- cally laminated composite plates. Compos. Struct. 9, 215-246 (1988).

11. B. N. Pandya and T. Kant, Higher-order shear deformable theories for flexure of sandwich plates-finite element evaluations. Int. J. Solids Struct. 24, 1267-1286 (1988).

12. T. Kant and B. S. Manjunatha, An unsymmetric FRC laminate $C^{0}$ finite element model with twelve degrees of freedom per node. Int. J. Engng Comput. 5, 300-308 (1988).

13. T. Kant and B. S. Manjunatha, Higher-order theories for symmetric and unsymmetric fibre reinforced composite beams with $C^{0}$ finite elements. Finite Elements in Analysis and Design 6, 303-320 (1990).

14. J. N. Reddy, A simple higher-order theory for laminated composite plates. ASME J. Appl. Mech. 51, 745-752 (1984).

15. N. D. Phan and J. N. Reddy, Analysis of laminated composite plates using a higher-order shear deformable theory. Int. J. Numer. Meth. Engng 21, 2201-2219 (1985).

16. N. S. Pucha and J. N. Reddy, A refined mixed shear flexible finite element for the nonlinear analysis of laminated plates. Comput. Struct. 22, 529-538 (1986).

17. M. V. V. Murthy, An improved transverse shear deformation theory for laminated anisotropic plates. NASA technical paper-1903 (1981).

18. M. Levinson, A new rectangular beam theory. J. Sound Vibr. 74, 81-87 (1981).

19. J. G. Ren and E. Hinton, The finite element analysis of homogeneous and laminated composite plates using a simple higher-order theory. Commun. appl. Numer. Meth. 12, 217-228 (1986).

20. J. J. Engblom and O. O. Ochoa, Through the thickness stress predictions for laminated plates of advanced composite materials. Int. J. Numer. Meth. Engng 21, 1759-1776 (1985).

21. J. J. Engblom and O. O. Ochoa, Finite element formulation including interlaminar stress calculations. Comput. Struct. 23, 241-249 (1986).

22. N. J. Pagano, Exact solution for composite laminates in cylindrical bending. J. Compos. Mater. 3, 398-411 (1969).

23. N. J. Pagano, Exact solution for rectangular bidirectional composites and sandwich plates. J. Compos. Mater. 4, 20-34 (1970).

24. J. G. Ren, A new theory of laminated plate. Compos. Sci. Technol. 26, 225-239 (1986).

25. J. G. Ren, Bending of a simply supported, antisymmetrically laminated rectangular plate under transverse loading. Compos. Sci. Technol. 28, 231-243 (1987).

26. J. M. Whitney, Bending-extensional coupling in laminated plates under transverse loading. J. Compos. Mater. 3, 20-28 (1969).

27. G. J. Turvey, Bending of laterally loaded, simply supported, moderately thick, antisymmetrically laminated rectangular plate. Fibre Sci. Technol. 10, 211-232 (1977).

28. H. G. Allen, Analysis and Design of Structural Sandwich Panels. Pergamon Press, London (1969).

29. D. S. Cairns and P. A. Lagace, Thick composite plates subjected to later loading. ASME J. Appl. Mech. S4, $611-616$ (1987)

30. M. G. Salvadori and M. L. Baron, Numerical Methods in Engineering. Prentice-Hall, Englewood Cliffs, NJ (1961).

31. S. P. Timoshenko and J. N. Goodier, Theory of Elasticity, 3rd Edn. McGraw-Hill, New York (1982). 